\title{
Functional GI disorders: from animal models to drug development
}

\author{
E A Mayer, ${ }^{1}$ S Bradesi, ${ }^{2}$ L Chang, ${ }^{2}$ B M R Spiegel, ${ }^{3}$ J A Bueller, ${ }^{2}$ B D Naliboff ${ }^{4}$
}

${ }^{1}$ UCLA Center for Neurovisceral Sciences \& Women's Health, Departments of Medicine Physiology and Psychiatry, David Geffen School of Medicine at UCLA, Los Angeles, CA, USA;

${ }^{2}$ UCLA Center for Neurovisceral Sciences \& Women's Health, Departments of Medicine, David Geffen School of Medicine at UCLA, Los Angeles, CA, USA; ${ }^{3}$ UCLA Center for Neurovisceral Sciences \& Women's Health, Departments of Medicine, Center for Outcomes Research and Education, David Geffen School of Medicine at UCLA, Los Angeles, CA and VA Greater Los Angeles Healthcare System, LoS Angeles, CA, USA; ${ }^{4}$ UCLA Center for Neurovisceral Sciences \& Women's Health Departments of Medicine and Psychiatry, David Geffen School of Medicine at UCLA, Los Angeles, CA and VA Greater Los Angeles Healthcare System, Los Angeles, CA, USA

\section{Correspondence to:}

Professor E A Mayer, UCLA Center for Neurovisceral Sciences \& Women's Health, VAGLAHS, Bldg. 115, Room 223, 11301 Wilshire Blvd, Los Angeles, CA 90073, USA; emayer@ucla.edu

Revised 27 August 2007 Accepted 8 September 2007 Published Online First 19 October 2007

\section{ABSTRACT}

Despite considerable efforts by academic researchers and by the pharmaceutical industry, the development of novel pharmacological treatments for irritable bowel syndrome (IBS) and other functional gastrointestinal (GI) disorders has been slow and disappointing. The traditional approach to identifying and evaluating novel drugs for these symptom-based syndromes has relied on a fairly standard algorithm using animal models, experimental medicine models and clinical trials. In the current article, the empirical basis for this process is reviewed, focusing on the utility of the assessment of visceral hypersensitivity and GI transit, in both animals and humans, as well as the predictive validity of preclinical and clinical models of IBS for identifying successful treatments for IBS symptoms and IBS-related quality of life impairment. A review of published evidence suggests that abdominal pain, defecation-related symptoms (urgency, straining) and psychological factors all contribute to overall symptom severity and to health-related quality of life. Correlations between readouts obtained in preclinical and clinical models and respective symptoms are small, and the ability to predict drug effectiveness for specific as well as for global IBS symptoms is limited. One possible drug development algorithm is proposed which focuses on pharmacological imaging approaches in both preclinical and clinical models, with decreased emphasis on evaluating compounds in symptom-related animal models, and more rapid screening of promising candidate compounds in man.

Despite the tremendous efforts by academia and industry alike during the past 15 years, the success rate for effective drug development for irritable bowel syndrome (IBS) and other functional gastrointestinal (GI) disorders (FGIDs) remains unimpressive. Only two new IBS treatments-that is, alosetron and tegaserod-have gained initial Food and Drug Administration (FDA) approval as a new IBS treatment so far. However, both of these medications are only available in the USA as part of a restricted access programme, due to side effects. ${ }^{1}$ Of the many failed compounds that never saw the light of the peer-reviewed literature, only a small number were officially announced as a failure, including the peripheral visceral $\kappa$-opioid agonist fedotozine, the selective $\mathrm{m}_{3}$ muscarinic receptor antagonist darifenacin and the selective $\mathrm{NK}_{3}$ receptor antagonist talnetant. Despite this discouraging news, and despite the fact that several major companies have decided to leave the IBS field altogether, several new and promising compounds are in various stages of early clinical development. $^{23}$
There have been advances in the field including development of agreed upon definitions of the major syndromes (as well as a myriad of other FGIDs), ${ }^{4}$ animal models with some face and construct validity for the human syndrome ${ }^{5}$ and identification of a continuously increasing number of molecular targets on epithelial and immune cells and visceral afferent neurons, ${ }^{6}$ and in the central nervous system (CNS). ${ }^{3}$ Furthermore, several potential "biomarkers" have been postulated in IBS patients (ranging from abnormal bacterial flora $^{7}$ to mucosal immune activation (reviewed in Spiller et $a l^{8}$ ) and abnormal perceptual and brain responses (reviewed in Mayer et al ${ }^{9}$ ). Despite the lack of an agreed upon pathophysiology, a standard strategy for drug discovery, including preclinical and clinical studies on GI motility and colorectal sensitivity, as well as large phase II and III efficacy trials, have been followed by most of the pharmaceutical companies involved in this field.

Why have these accomplishments not translated into more effective treatments? Is there a fundamental flaw in the drug discovery and development strategies that have been followed during the past decade? Is it premature to embark on costly drug development strategies for complex symptom-based disorders like IBS or other FGIDs as long as a full understanding of the pathophysiology of these syndromes is not available and the treatment targets remain "moving targets"? The situation is further complicated by rapid advances in the scope and speed of drug discovery efforts in the pharmaceutical industry over the past decade so that the field is now faced with a rapidly growing number of candidate compounds emerging from preclinical development without a cost-effective strategy to screen these compounds efficiently for their usefulness in human patients.

In the following review, we will focus on the "process" of drug development in IBS, by critically reviewing three areas in the current assumptions and strategies of drug development efforts in IBS: (1) What is the current approach to drug development in IBS, and what is the strength of the evidence supporting this approach? (2) What is the predictive validity of commonly employed experimental medicine models for IBS symptoms. (3) What is the predictive validity of existing animal models and the molecular targets identified in these models for the human disorder? Based on this review, we are proposing possible modifications in the existing strategies which could avoid the pitfalls of the past and present, and hopefully translate into more cost-effective development 
strategies for this important area of gastroenterology.

\section{THE CURRENT APPROACH TO DRUG DEVELOPMENT}

The current approach to drug development for IBS and other FGIDs is illustrated in fig 1. Syndromes are defined by their primary symptoms, in the case of IBS in terms of chronically recurring abdominal pain or discomfort associated with alterations in bowel habits ${ }^{4}$ (fig 1A). Human biological markers including perceptual hypersensitivity to experimental rectal or sigmoid distension (referred to throughout as "visceral hypersensitivity"), and altered intestinal transit (whole gut or regional colonic transit) which are thought to underlie specific IBS symptoms serve as a basis for the development of animal models (nociceptive reflex responses to colorectal distension, faecal pellet output or transit studies) which in turn aim to mimic the human biomarkers or intermediate phenotypes (fig 1C). ${ }^{10}$ Molecular targets are identified in these animal models which are thought to mediate the characteristic features exhibited by the animal model (eg, ion channels and receptors on visceral afferent neurons, enterochromaffin cells, enteric neurons, central stress circuits). Highly selective, candidate compounds aimed at these molecular targets are developed and optimised (fig 1E), which in turn are tested in the respective animal models and, if shown to be effective and safe, are tested in human experimental medicine models (phase I and IIa) for their ability to affect

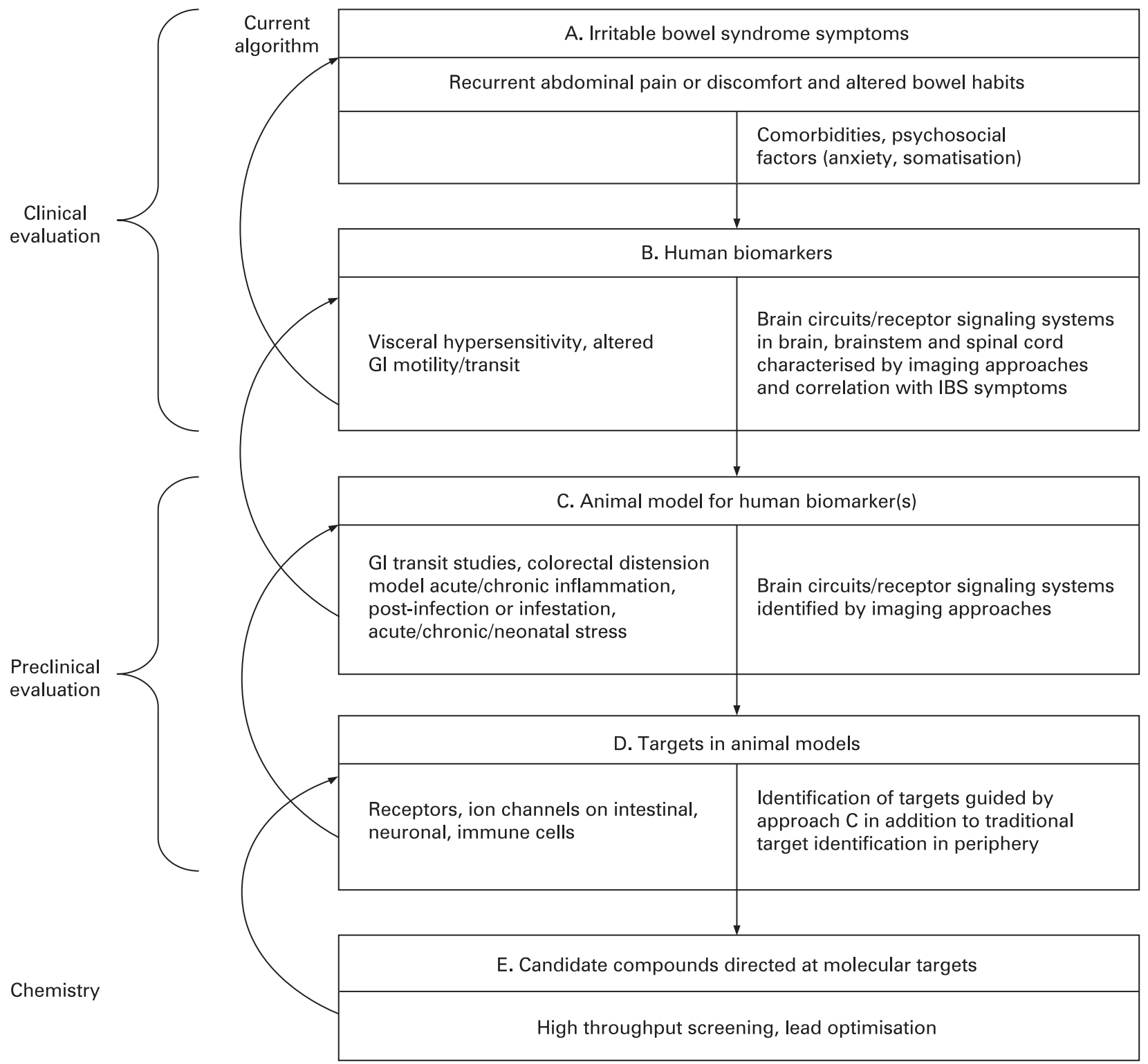

Proposed algorithm

Figure 1 General strategy in irritable bowel syndrome (IBS) drug discovery and development. The schematic illustrates the vertical progression from the symptom complex of IBS to target identification in animal cells. For each step the current approach is shown in the left portion of the boxes. In the right portion of each box, suggested modifications to the current approach are shown. The current approach is lengthy, expensive and based on poor correlations between the individual steps. Gl, gastrointestinal. 
GI transit or visceral sensitivity. Either sequentially or in parallel, candidate compounds are being evaluated in small proof of concept (POC) studies (phase IIa) and large phase II/III multicentre studies, using global (as opposed to specific symptom-related) end points, in particular the adequate relief end point. ${ }^{11}$

Even though this drug development approach appears to be rational at first glance, the fact that it has not proven to be more successful or costeffective for IBS may be related to several major flaws in its logic.

\section{Translation of human symptom-based disorder into human biomarkers (fig 1A)}

In contrast to most organic diseases with identifiable lesions or biochemical abnormalities, so-called functional syndromes have traditionally relied on subjective, symptom-based outcome measures. In parallel to attempts to refine these symptom criteria, a major effort has been underway during the last decade to identify surrogate biomarkers for FGIDs, which can be used as more objective end points for drug evaluation. The ideal surrogate marker would be seen in most affected patients (or a clearly identifiable subset of patients), its demonstration would be independent of a particular laboratory, it would exhibit high test-retest reliability both within and between patients, and, most importantly, would correlate highly with either a specific IBS symptom or, preferably, with global IBS symptom severity or health-related quality of life (HRQoL) - that is, the factors that ultimately determine if an individual becomes a healthcare-seeking IBS patient. The finding of an abnormality without a high correlation with symptom severity (eg, mucosal immune activation $^{12}$ ) may be interesting from a scientific standpoint to understand IBS pathophysiology better or to identify subgroups of patients, but such a finding probably does not have particular value for predicting drug effectiveness or determining optimal drug dose. Examples of the latter include non-specific alterations in GI motility, altered number of enterochromaffin cells, intraepithelial lymphocytes or plasma cortisol values. There has been reported a correlation of abdominal pain with the number of mucosal mast cells in close proximity to nerve endings, ${ }^{13}{ }^{14}$ but this finding will need to be reproduced by other laboratories before it can be considered a true biomarker of IBS symptoms. Potential biomarkers for which correlation with IBS symptoms have not been published include recently reported abnormalities in stool microflora ${ }^{7}$ and in stool proteases. ${ }^{15}$

The assessment of a good surrogate marker in validated experimental paradigms in human subjects should have a high validity in predicting the effectiveness of a compound in the treatment of IBS symptoms. Based on the cardinal symptoms of IBS (abdominal pain/discomfort, altered bowel habits), a series of such experimental medicine models have been developed and used in the drug development process during the past 10 years.
However, before accepting the most commonly used surrogate markers for abdominal pain and for altered bowel habits as meeting the requirements of predicting the effectiveness of a candidate drug on IBS, several points have to be considered. The best and most commonly used subjective end point to assess IBS drug effectiveness is global end points, including the adequate relief end point. ${ }^{4}$ While the gold standard in IBS clinical trials, such global end points do not employ specific symptom-based "readouts", but rather a subjective value judgement (eg, how an individual patient feels that her/ his symptoms have been relieved adequately), which could be correlated with surrogate markers. Surprisingly, despite decades of IBS drug development, there is uncertainty and few data to demonstrate how best to measure IBS severity. A preliminary report identified several predictors for patient-assessed "overall severity of gastrointestinal symptoms". ${ }^{16}$ As hypothesised, the predictors included multiple symptoms, such as ratings of abdominal pain and discomfort (bloating), defecation-related symptoms (straining, urgency) and a symptom-related anxiety ("something serious is wrong with my body"). These factors jointly accounted for only one-third of the variance of IBS severity. Therefore, there are other factors which were not specified in this model or have not been measured. However, within this group of predictors, abdominal pain was the most powerful predictor of severity. The association between abdominal pain and severity was almost three times as strong as the next closest predictor, which was "something serious is wrong with my body". A recent study identified several predictors of IBSrelated HRQoL impairment. ${ }^{17}$ Surprisingly, alteration in bowel habits was not identified as a significant predictor of HRQoL, while several non-GI symptoms, such as vital exhaustion and symptom-related anxiety, were identified. These factors jointly accounted for $39 \%$ of the variance of HRQoL. Amongst the symptom predictors of HRQoL, symptoms of vital exhaustion such as low energy and tiring easily were the most important predictors of physical HRQoL, followed closely behind by overall symptom severity. Feeling tense was the most important predictor, followed by nervousness and hopelessness for mental HRQoL. Assuming that the global end points used in clinical trials ("did you get adequate relief of your bowel symptoms") are influenced by both IBS severity and IBS-related HRQoL impairments, it is likely that a range of factors including measures of abdominal pain or discomfort, defecation-related symptoms and psychological symptoms contributes to the way we currently measure the effectiveness of IBS drugs. If this hypothesis is correct, successful pharmacological relief of one of these components will result in only moderate global symptom relief, while pharmacological relief of two or more of these factors should result in a highly effective drug. The identification of other predictors of severity and $\mathrm{HRQoL}$ impairment is likely to improve the model and in fact may lead to 
new surrogate markers for drug development. An alternative or complementary approach would be the identification of CNS correlates of IBS symptom severity or of adequate relief, using the respective brain circuits as objective surrogate markers (see also final section). This hypothesis is illustrated in fig $2 \mathrm{~B}$.

In the following, we will focus on the two most commonly used surrogate markers for which evidence for correlation of human biomarkers with clinical IBS symptoms is available: enhanced perceptual responses to controlled rectal or sigmoid distension (referred to from hereon as "visceral hypersensitivity") and gut transit studies,

\section{Visceral hypersensitivity as a biomarker for IBS}

Visceral hypersensitivity has been the most widely used and perhaps most controversial of the "biological" markers of IBS. In fact, in humans the metric of sensitivity is almost always based on a subjective report and, therefore, is an indirect measure of a hypothesised neurophysiological process. Traditionally, basic scientists have extrapolated from results obtained from visceral afferent recordings and pseudoaffective reflex responses in animals to relevance for the treatment of enhanced visceral perception and IBS symptoms in patients. However, it has to be kept in mind that what can be assessed in human subjects is mostly the subjective sensitivity to experimental stimuli in a safe environment, and not measures of afferent sensitivity for stimuli directly related to clinical symptoms. ${ }^{18}$ Given the considerable number of cognitive and emotional variables that influence the ultimate experience of the sensation, it can be assumed that the relationship between visceral afferent sensitivity and perception is highly nonlinear. The peripheral stimulus for testing visceral sensation is most often a mechanical distension using an air-filled bag and a computer-controlled pump (or barostat), but may also include electrical or chemical stimuli. ${ }^{19}$ Both the type and the characteristics of the stimulus (eg, slow increasing ramp distension vs square wave phasic distension) as well as its predictability can significantly impact the outcome of experiments independent of the absolute amount of pressure or volume. ${ }^{20} 21$

\section{Is visceral sensitivity a reliable marker of IBS?}

For over 30 years visceral hypersensitivity to balloon distension has been described as a characteristic of IBS. ${ }^{22}$ Visceral hypersensitivity could in principle result from a number of peripheral (eg, mucosal immune activation, mast cell degranulation, altered flora) as well as from central mechanisms. A large number of papers have compared groups of IBS patients with controls using various distension procedures, and several generalisations can be made from this heterogeneous group of studies. $^{18}$

- IBS patients as a group typically show lower average thresholds for pain or discomfort than healthy controls in response to brief (30-60 s) phasic rectal distensions. ${ }^{21}$ 23-28

- About $40-60 \%$ of IBS subjects show baseline hypersensitivity when this is defined as a pain or discomfort threshold to phasic distensions lower than the $95 \%$ CI of a healthy control group. ${ }^{29}$ Bouin et $a^{24}$ studied a large clinic sample of IBS patients ( $\mathrm{n}=86,60$ females, 26 males) and examined the sensitivity and specificity of an ascending phasic distension test (ie, a paradigm which maximises hypervigilance) for separating IBS patients from healthy subjects and other GI patients with inflammatory bowel disease, functional constipation, etc. They found an $80 \%$ specificity and a $90.7 \%$ sensitivity at a $40 \mathrm{~mm} \mathrm{Hg}$ threshold (86.3\% efficiency) for separating IBS and controls, and similar values for comparing IBS with the combined GI patients $(86.8 \%$ efficiency at $40 \mathrm{~mm} \mathrm{Hg}$ ).

- IBS patients do not show the same hypersensitivity to slow ramp inflations compared with controls, ${ }^{30}{ }^{31}$ and may even be less sensitive to such stimuli than healthy controls. ${ }^{23} 25$ Similarly, IBS patients seem to demonstrate somatic hypersensitivity when tested with tonic heat stimuli, ${ }^{27}$ but normosensitive or hyposensitive to phasic electrical or pressure stimuli. $^{32}{ }^{33}$

- IBS patients, in particular female patients, demonstrated enhanced perceptual responses to repeated distensions in the rectum and sigmoid colon, suggesting that abnormal sensitisation or temporal summation of visceral stimulation may also be a marker of the disorder. $^{34-37}$

In summary, hypersensitivity based on barostat assessment using phasic stimuli and a subjective "readout" does show specificity for IBS, although there is considerable variability across patients and between different laboratories, and overlap with non-patient samples.

\section{The role of hypervigilance in visceral hypersensitivity}

Clearly a significant component of perceptual hypersensitivity seen in the IBS studies described above is due to attentional processes that can be described as hypervigilance to visceral sensations. ${ }^{21}$ Experimental designs that use non-random presentation of stimuli (eg, those that use an ascending series of distensions) tend to foster response bias in that subjects can give appropriate responses without paying close attention to the actual sensation. IBS subjects may be particularly prone to such bias due to anxiety, even though it is currently not known if this type of anxiety is a primary factor or has developed as a consequence of chronic pain. Although non-random and random procedures are often correlated, in general, differences between IBS and controls are greater in studies using ascending versus randomly presented stimuli. ${ }^{21} 2634$ 38-40 In addition, even with randomly presented stimuli, IBS patients show significant 
A

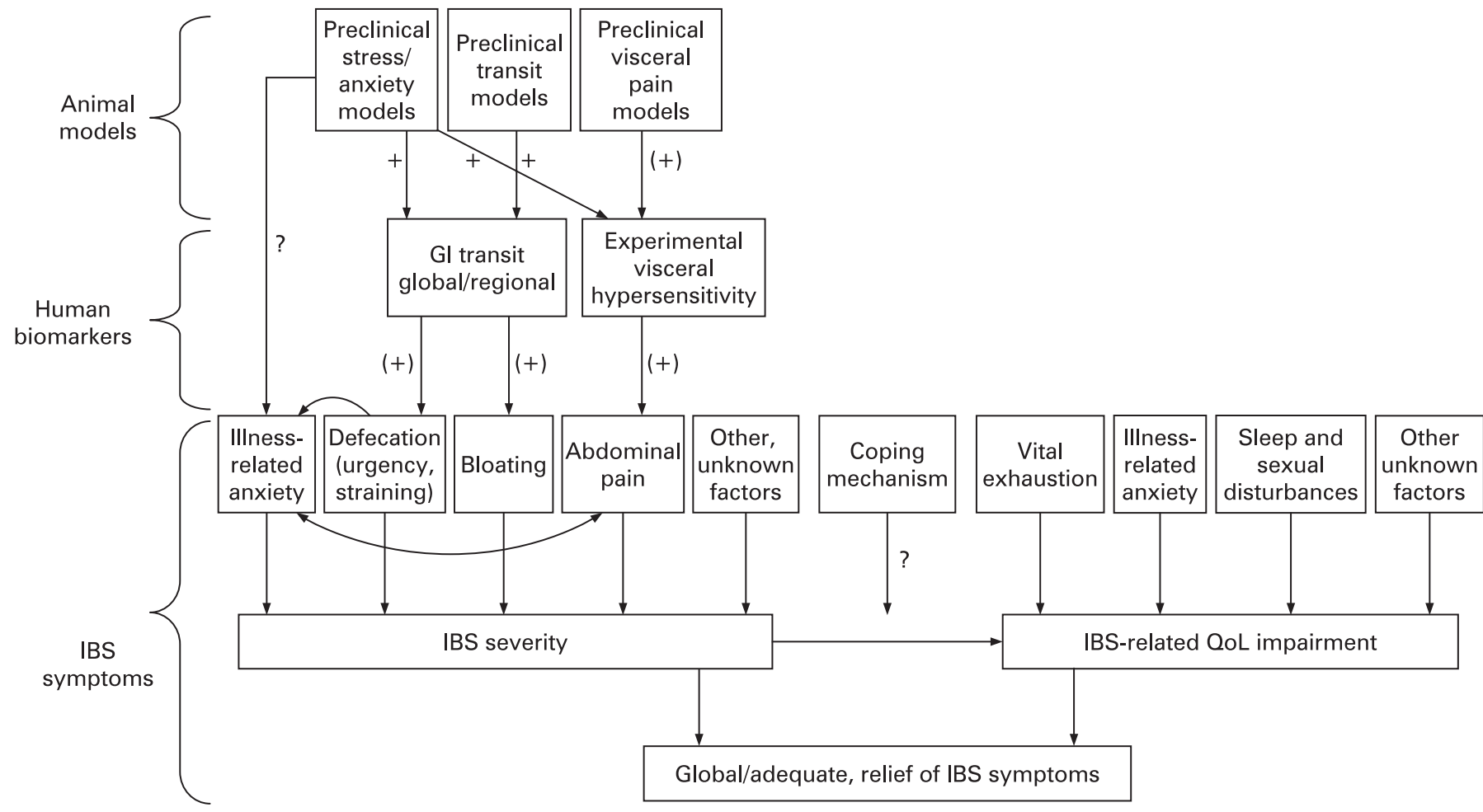

B

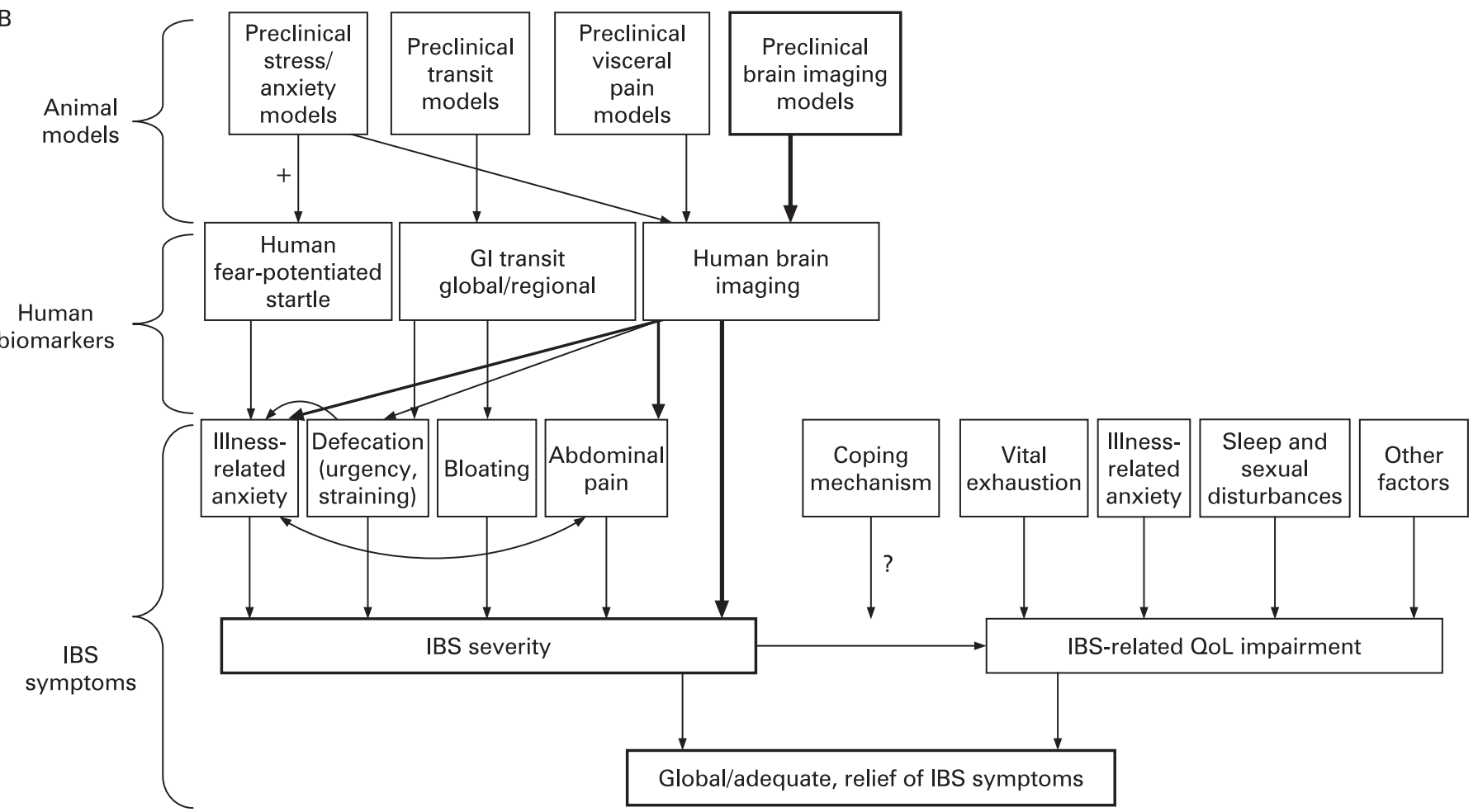

Figure 2 Progression from animal models to human biomarkers to human symptoms and health-related quality of life ( $0 \mathrm{oL})$ impairment. (A) Current concept. Shown are commonly used assays and measures at these three levels of investigation. Arrows denote correlations/predictive validity from the lower to higher level. Signs next to arrows denote strength of connections: + good, (+) weak, ? not known. (B) Proposed concept. Shown is a proposed modified version of $(A)$, with greater emphasis on brain imaging approaches at both the preclinical and clinical level. The correlations between preclinical and clinical brain imaging approaches, symptom severity and health-related $\mathrm{OoL}$ are currently not known (for details, see also fig 3). IBS, irritable bowel syndrome; Gl, gastrointestinal. 
habituation of responses with repeated exposure to rectal distensions, ${ }^{28}$ and perception of distensions increases during even mild psychological stress, ${ }^{41}$ demonstrating the influence of affective and cognitive factors on visceral perception beyond simple judgemental bias. This view is consistent with brain imaging results showing greater activation in emotional arousal regions, and habituation of such hyperarousal with repeated stimulus application. ${ }^{28}$

\section{Correlation of visceral sensitivity with clinical symptoms (IBS symptoms, symptom severity, psychological symptoms)}

Despite the large literature comparing visceral sensitivity across patient and non-patient groups, there are very few data examining the relationship between these measures and IBS symptom severity. Of the few studies that have reported these data, the relationships appear to be small or nonexistent. Two studies, reported in abstract form, suggest that the correlation between pain symptoms and rectal and sigmoid sensitivity range between 0.3 and 0.4 - that is, only between 9\% and $16 \%$ of abdominal pain symptoms are explained by rectosigmoid sensitivity during experimental distension. ${ }^{42}{ }^{43}$ Several more recent studies have also reported a significant positive relationship between a visceral sensitivity measure and abdominal pain symptoms. ${ }^{44}{ }^{45}$ There are no clear data relating visceral sensitivity observed during barostat-mediated rectal distension and more global IBS symptoms, and in fact several studies have shown a lack of such a relationship. ${ }^{23}{ }^{34}{ }^{46}$ There is a larger literature examining the relationship between visceral sensitivity and bowel habit; however, the results have not been consistent. Some studies have found increased sensitivity in diarrhoea-predominant patients compared with those with constipation, but other studies have found the opposite or no differences (see Stacher et $\left.a l^{47}\right)$. In addition, there are no clear data on the relationship of severity of bowel habit and measures of sensitivity. A recent study suggests that the hypersensitivity seen in IBS patients is primarily seen in female patients. ${ }^{35}$

\section{Predictive validity of visceral sensitivity testing for FGID drug development}

Table 1 lists studies using visceral perception testing procedures to evaluate the potential benefits of candidate drugs as visceral analgesics and as potential medications for treating IBS symptoms. From these publictions, several important conclusions can be drawn with regard to this experimental medicine procedure for IBS drug development. (1) Visceral sensitivity tests clearly show robust analgesic responses to $\mu$ - and $\kappa$-opiate analgesics in small crossover samples such as used in typical trials. ${ }^{4048} 6771$ These studies support the viability of distension procedures in the rectum (and probably the stomach as well) to detect acute changes in analgesia. In other words, the barostat test is a valid human experimental model for visceral pain. It should also be noted that the perceptual differences in these studies were independent of changes in compliance or tone. (2) To be useful as a surrogate marker, visceral testing should be helpful in discriminating medications that do or do not have a positive impact on either specific or global IBS symptoms. This criterion is often referred to as the ability to reach a go/no-go decision based on the test results. Data from multiple classes of drugs have now been compiled and often there is little predictability between the two types of outcomes, with some drugs showing positive changes on visceral sensitivity testing by barostat, but no change on symptoms, and vice versa (see Kuiken et al. ${ }^{72}$ ).

Some compounds, such as the $\kappa$-opioid-preferring antagonist fedotozine, have a significant effect on visceral testing in some studies, and also seemed to impact IBS symptoms positively in initial small clinic studies. ${ }^{49} 50$ However, further development was not pursued, presumably due to lack of efficacy in well-designed phase II clinical trials. Similarly, the synthetic somatostatin analogue octreotide consistently showed visceral analgesic and antihyperalgesic properties during laboratory testing. Preliminary evidence from an 8-week controlled clinical treatment trial $^{68}$ showed that octreotide treatment was associated with a reduction in the perception of barostat-induced rectal distension in non-constipated IBS patients, as well as a reduction in abdominal complaints and improved stool consistency. The NK3 receptor antagonist talnetant had no effect on visceral perception (or mechanoelastic parameters of the rectum) in a large well-designed study in healthy volunteers $^{61}$ (it was never tested in IBS patients), and had no significant effect on IBS symptoms in two well-designed randomised controlled trials (RCTs). ${ }^{60}$ On the other hand, the $5-\mathrm{HT}_{3}$ receptor antagonists including ondansetron and alosetron have shown no direct effect on percep-

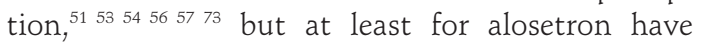
shown positive effects on global IBS symptoms. ${ }^{52}$ Similarly, the $5-\mathrm{HT}_{4}$ receptor agonist, tegaserod, is another serotonergic compound that has shown some efficacy on global IBS symptoms but no clear change in studies on human visceral sensitivity. ${ }^{74}$ Since these compounds are likely to affect serotonin modulation of GI motility and secretion, and in the case of alosetron possible CNS mechanisms related to anxiety, ${ }^{75}$ it is likely that for many drugs their impact on IBS global symptoms is not via the presumed "visceral analgesic mechanism" but instead through their effect on central or peripheral autonomic (including enteric nervous system) pathways. Antidepressants including tricyclics have not been well studied in visceral sensitivity tests, but there is little evidence that they decrease the perception of noxious rectal distension per se, even though they have been found to have a small to moderate therapeutic effect on IBS symptoms. $^{3}{ }^{33}$ 


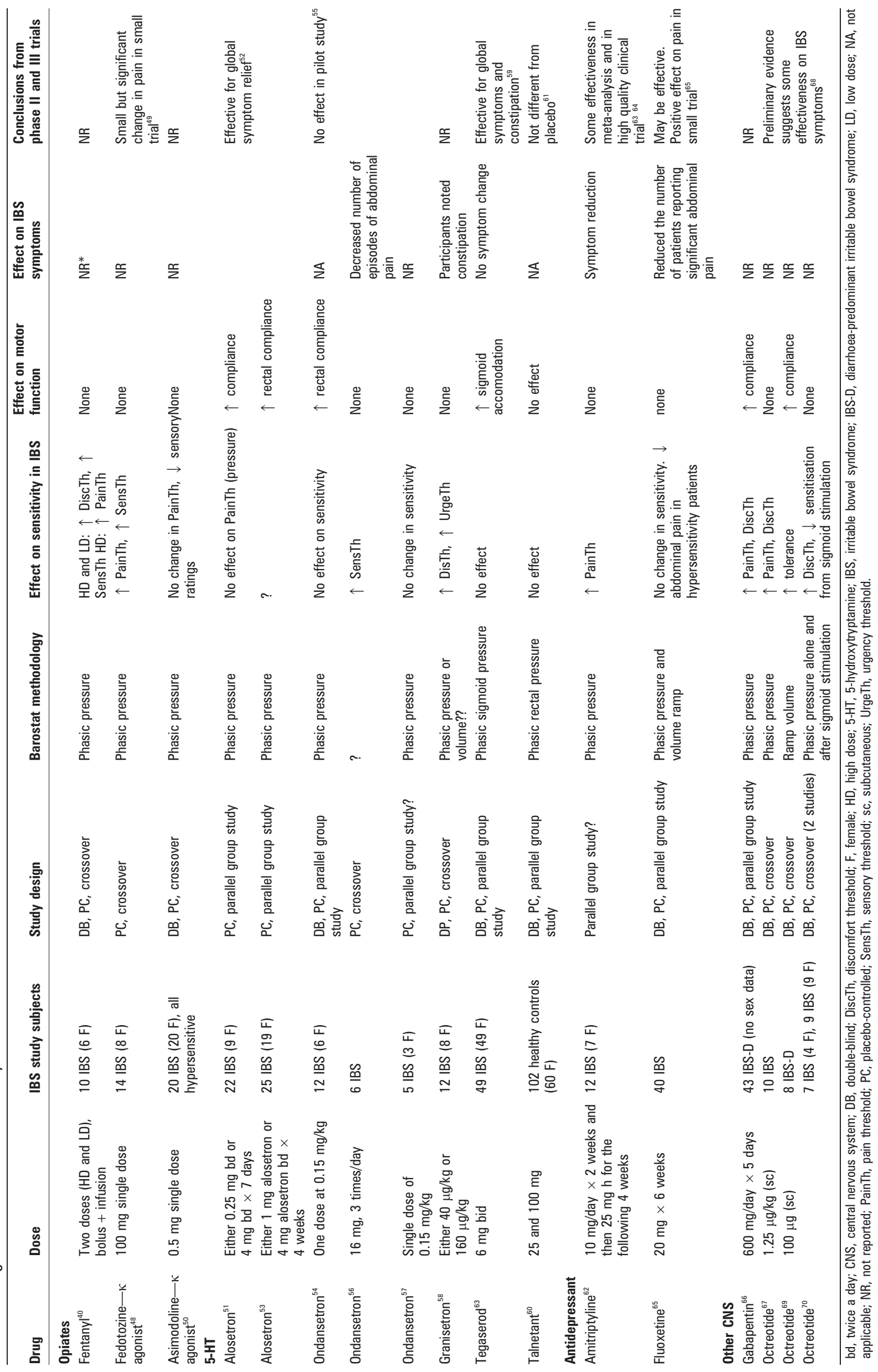


How then does visceral sensitivity testing fare against the criteria for a biomarker presented above?

- It is clear that a majority of IBS (and probably functional dyspepsia) patients show hypersensitivity to at least phasic distension, although a substantial minority do not show this abnormality. No specific clinical characteristic has been identified that would differentiate the hypersensitive and normosensitive patients, with the possible exception of female sex. Mucosal immune activation, differences in bacterial flora or genetic factors may all be contributing to this heterogeneity.

- The barostat techniques do appear to be reliable across labs, with much consistency for manipulations (eg, analgesics) that should directly impact responding.

- The results are reproducible in a single subject at least for two testings, as evidenced by the success of crossover studies; however, newer data show gradual habituation over multiple testing. ${ }^{28}$

- Visceral sensitivity testing has not been shown to be reliably associated with acute or chronic symptom intensity. Unfortunately, there are actually few data on this relationship, but to date there is no evidence for a relationship with global symptoms, a small set of data indicating some relationship with abdominal pain, and inconsistent data from compounds that either do or do not impact clinical symptoms.

Overall, the barostat-mediated distension of the human gut emerges as a potentially reliable and valid approach to test perception of visceral sensation and changes in visceral perception. However, it is most important in the formulation of a trial design to understand that the subjective (perceptual) and objective (mechanoelastic) responses obtained in this invasive and lengthy test are not highly related to global or even specific IBS symptoms (such as pain) and, therefore, when used by itself, may not be suitable to make socalled go/no-go decisions in drug development. There has also been some interest in examining the lower limb (or RIII) nociceptive reflex as a potential objective marker of visceral sensitivity. ${ }^{29}$ The RIII is decreased during slow ramp distension of either the stomach or rectum in healthy controls, a response that has been hypothesised to result from supraspinal modulation of the reflex as part of a "pain inhibiting pain" system referred to as descending noxious inhibitory controls (DNICs). This RIII technique has been used in one study of Tegaserod $^{71}$ and has shown alterations in IBS (increased RIII during a ramp rectal distension). However, while of interest, it has not to date been validated sufficiently as a marker of visceral hypersensitivity in patient populations or with any other medications.

\section{GI transit as a biomarker for the IBS symptom: altered bowel habits}

In general, subjective reports of constipation or diarrhoea have been associated with alterations in
GI transit, and measurements of global or regional GI transit have been used extensively to evaluate candidate drugs assuming a predictive value of such tests for drug effectiveness on IBS symptoms. However, while defecation-related symptoms (straining, urgency) were found to be predictive of IBS severity, ${ }^{16}$ altered bowel habits were not found to be an important factor in the impairment of HRQoL in a large survey of IBS patients. ${ }^{17}$ It is well known that the symptom of constipation may occur with or without slowing of colonic transit. ${ }^{76}$ In many patients complaining of constipation, particularly those with normal transit constipation, it may be more a sensory symptom of "feeling" constipated, rather than a symptom of altered motility or secretion. In such patients, using the "objective" marker of gut transit would be expected to show poor correlation with overall IBS symptoms.

\section{Transit studies to quantitate intestinal motility}

Gut transit refers to the time taken for food or other material to pass through the GI tract. Transit is a clinically relevant and convenient measure of GI function primarily related to GI motility and secretion. ${ }^{77}$ There are various methods of measuring GI transit, and the more commonly used techniques in clinical studies are radio-opaque markers and scintigraphy (reviewed in Camilleri et $a l^{78}$ and Metcalf et $a l^{79}$ ). Validation of the radioopaque marker study to evaluate gut transit was performed by comparing the three different markers used in a group of healthy individuals. ${ }^{79}$ The mean colon transit times as measured by the three different markers correlated fairly well $(r=0.69$ 0.89). The variability in transit times within an individual was thought to reflect true day-to-day variation. The authors suggested that for clinical purposes only major differences from normal values can be accepted as a significant finding. The reproducibility of scintigraphy was assessed in 21 healthy individuals over a 3 -week period of time. $^{80}$ Gastric emptying at $4 \mathrm{~h}$ was highly reproducible (coefficient of variation was $4 \%$ ) on repeat testing. The colonic measurement was less reproducible and varied by more than one geometric centre unit in $37 \%$ of subjects at $24 \mathrm{~h}$ and in $26 \%$ of subjects at $48 \mathrm{~h}$. Furthermore, in almost $75 \%$ of subjects, the residuals for colonic transit by scintigraphy were within one geometric centre in up to $72 \%$ of subjects across the range of mean colonic transit times by radio-opaque markers. ${ }^{80}$ The sample sizes for scintigraphic transit measurements needed to detect clinically meaningful differences were calculated and differed depending on the end point. The transit end points, which appeared to need the smallest number of subjects, were the percentage of gastric emptying at $4 \mathrm{~h}$ ( $n=6$ to detect a difference of $25 \%$ ) and the colonic geometric centre at $48 \mathrm{~h}(\mathrm{n}=14$ to detect a difference of 1.5 geometric centre units). A sample size of 23 was needed to detect a difference of 1.7 geometric centre units at $24 \mathrm{~h}$. 


\section{Do gut transit measurements correlate with IBS symptoms?}

There is evidence of accelerated gut transit in diarrhoea-predominant IBS (IBS-D) patients compared with normal values, although group sizes are relatively small in many of the studies. In one of the largest studies, Horikawa and colleagues compared gut transit times in 72 IBS patients (48 IBS-D, 24 constipation-predominant IBS (IBS-C)) and 23 healthy controls using radio-opaque markers. ${ }^{81}$ Total gut transit times were significantly accelerated in IBS-D patients compared with controls and IBS-C patients. Segmental colon transit times of the ascending, transverse, descending and rectosigmoid colon were significantly shorter in IBS-D than in the other two groups. However, there were no significant differences in transit times between the IBS-C and control groups. In another study, baseline orocaecal transit was shorter in six patients with IBS-D compared with eight healthy controls. ${ }^{82}$ This finding conflicted with another study which found that gastric emptying and small intestinal transit times measured by scintigraphy were not different between eight IBS-D patients and six controls. ${ }^{83}$ Vasallo and colleagues demonstrated in a study of 10 IBS-D patients that overall colonic transit was accelerated in seven patients (five also had rapid emptying of the proximal colon). ${ }^{84}$

Although gut transit measurements are not used specifically to identify IBS bowel habit subgroups, studies have shown that transit times differ between those with IBS-C and IBS-D, as was shown in Horikawa's study. ${ }^{81}$ Breath hydrogen tests showed significantly shorter small intestinal transit times in IBS-D patients and prolonged transit in IBS-C patients or those with predominant pain and distension. ${ }^{85}$ Psychological stress may accelerate orocaecal transit in IBS-D, but slow transit time in IBS-C. ${ }^{85}$ A scintigraphy study reported significantly faster ileocaecal transit in IBS-D than in IBS-C. ${ }^{86}$ Interestingly, the recently established Rome III subclassification of IBS is based on stool form (and not stool frequency), which shows good correlations with intestinal transit time. ${ }^{87-89}$ Stool form has been shown to differentiate IBS bowel habit subgroups best, ${ }^{90}$ particularly IBS with alternating bowel habits (IBS-A), ${ }^{91}$ but to date has not been found to be a significant predictor of overall IBS symptom severity. Constipated patients with delayed colonic transit may respond to treatment differently from patients with normal transit. ${ }^{77}$

A recently published study investigated if colon transit measured by radio-opaque markers in IBS patients correlated with symptoms in the Rome II diagnostic criteria. ${ }^{92}$ In 148 healthy control subjects and 1385 consecutive IBS patients, overall colonic transit time was measured, as were transit times for three segments of the colon (right, left and rectosigmoid). Fifty-four percent of IBS patients (12.3\% diarrhoea, $60.4 \%$ constipation, $27.7 \%$ alternating) and $91 \%$ of controls had normal overall colonic transit times $(<70 \mathrm{~h})$. There were no significant differences in overall colonic transit times between IBS patients and healthy controls within each gender group. However, a small subgroup of healthy men had slower right colon transit compared with men with IBS, and women with IBS had shorter transit times in the left colon and rectosigmoid colon compared with healthy women. In IBS patients with normal overall colonic transit times, cluster analysis revealed heterogeneity in segmental colon transit times in both controls and IBS patients. In IBS patients, there was no significant difference in clinical symptoms between the four different colonic transit cluster groups. However, another recent study in a much smaller group of IBS patients $(n=28)$ demonstrated that colonic transit was independently associated with bowel urgency. ${ }^{93}$ Those with bowel urgency had shorter colonic transit times, particularly in the left and rectosigmoid colon, than those without urgency. This is not unexpected since the patients with bowel urgency had IBS-D ( $\mathrm{n}=11$ of 13) and IBS-A $(n=2)$, while over half of the patients without urgency had IBS-C ( $n=8$ of 15$)$ and the remainder had IBS-D $(n=4)$ and IBS-A $(n=3)$. In summary, GI transit times (measured using radio-opaque markers) within the normal range do not appear to correlate well with bowel symptoms in IBS.

Gas transit has been measured in IBS patients with abdominal bloating. These patients were found to have impaired reflex control of gut handling of contents, which leads to gas retention and symptoms of bloating. However, the correlation of gas retention with subjective symptoms was poor. Total gut transit of gas was delayed due to impaired small bowel transit, whereas colonic transit was normal. ${ }^{94}$ 96 In IBS patients, intraluminal lipids impaired intestinal gas clearance, which was thought to be due to an upregulated reflex inhibition of small bowel transit, without significant colonic effects.

\section{How predictive are GI transit studies in the evaluation of candidate compounds aimed at overall IBS symptoms?}

There are a number of studies which have evaluated the effect of treatment interventions on GI transit in IBS. The studies which compared the effect of the therapeutic agent with baseline measurement or placebo in IBS patients are shown in table 2. These IBS therapies may prolong or shorten transit times in IBS depending on their mechanism of action and the IBS bowel habit subgroup in which they are being evaluated. However, only a few studies reported if the changes in transit times correlated with IBS symptoms. Using radio-opaque markers to measure colon transit, the bulking agent calcium carbophil was found to prolong colon transit time in IBS-D patients but reduce colon transit time in IBS-C patients compared with a drug-free baseline condition. The cholecystokinin (CCK)-1 antagonist dexloxiglumide slowed ascending colon emptying (and accelerated gastric emptying) as measured by scintigraphy but had no effect on overall colon transit time compared with placebo in 36 women with IBS-C. ${ }^{101}$ Colon transit time 


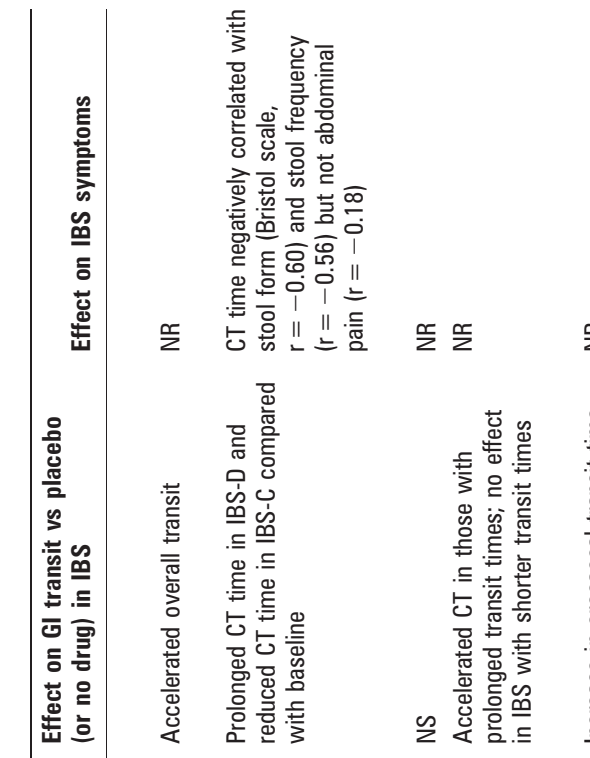

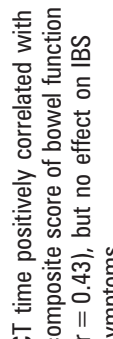
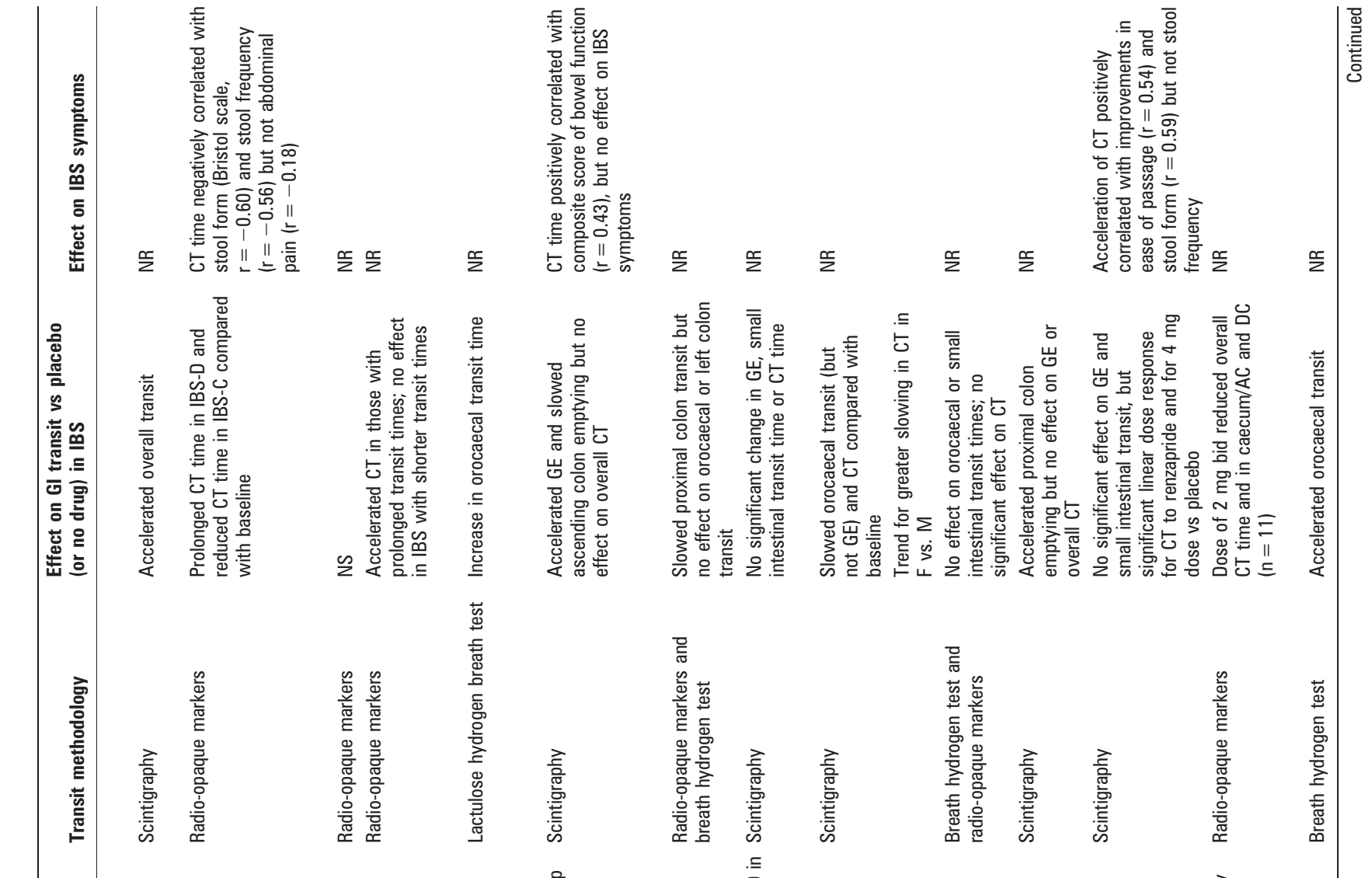

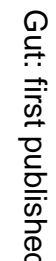
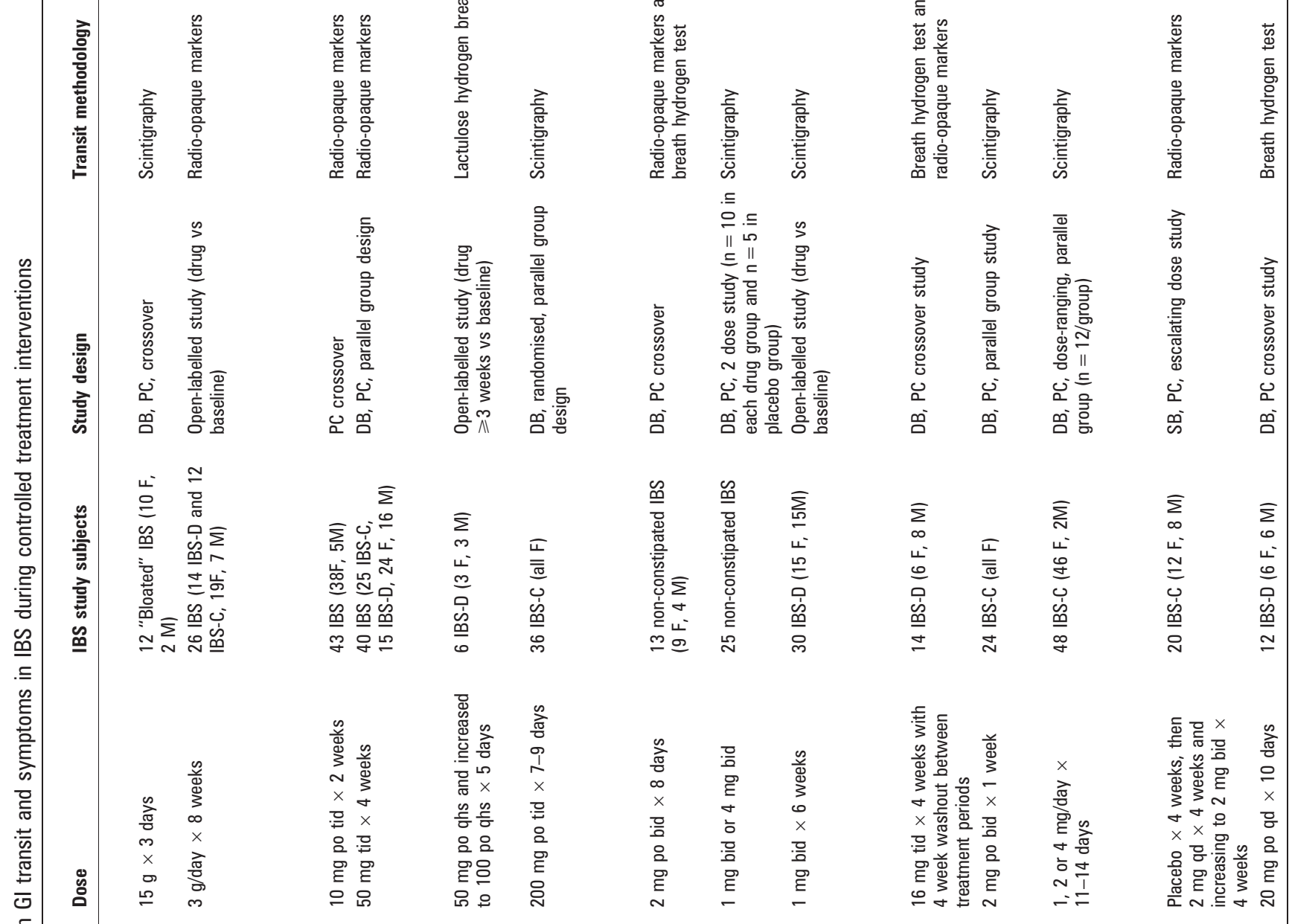

으
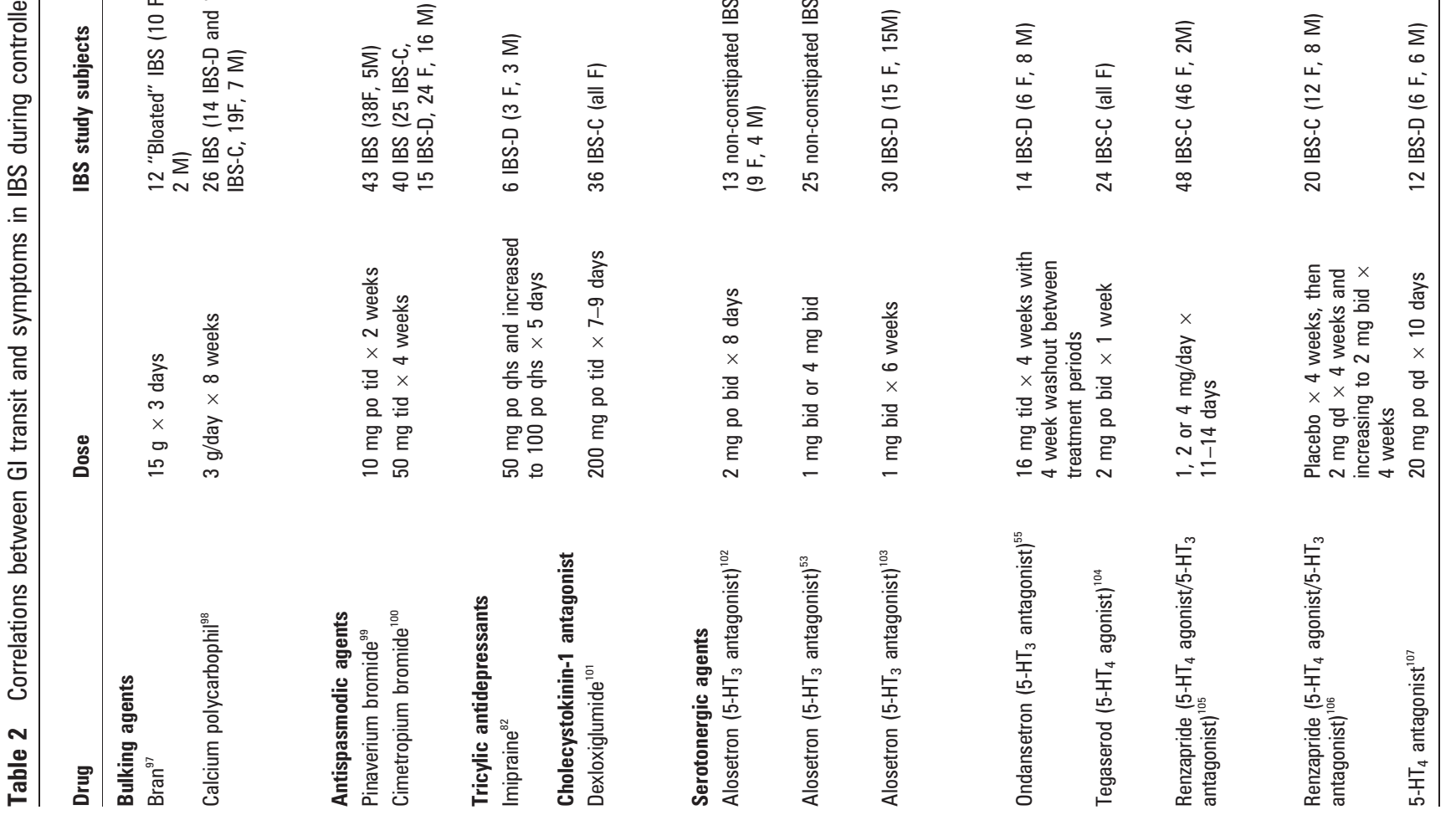
positively correlated with composite score of bowel function (ie, stool frequency and form, ease of passage and incomplete evacuation), but this effect on transit did not translate into efficacy for IBS-C symptoms in two, well-designed phase III RCTs. ${ }^{111}$ The composite score was scaled so that the higher score was associated with symptoms more associated with a diarrhoea-like pattern (ie, less formed stool, higher number of bowel movements per day and easier passage), and a lower score was associated with a constipation-like pattern. Renzapride is an investigational drug which is a combined $5-\mathrm{HT}_{4}$ agonist and $5-\mathrm{HT}_{3}$ antagonist, and is currently being assessed in phase III trials for IBS-C. In a double-blind, placebo-controlled, parallel group scintigraphic study in 48 patients with IBS-C ( $n=12 /$ group), there was a significant linear dose response for colon transit to renzapride (1, 2 or $4 \mathrm{mg} /$ day) and for $4 \mathrm{mg}$ dose versus placebo (but no significant effect on gastric emptying and small intestinal transit). ${ }^{105}$ Acceleration of colon transit positively correlated with improvements in ease of passage and stool form, but not with stool frequency. In another study, Tack et al ${ }^{106}$ found that renzapride at a dose of $2 \mathrm{mg}$ twice daily produced a statistically significant reduction in overall colonic transit measured with radio-opaque markers compared with placebo. IBS symptoms showed some improvement with renzapride compared with placebo but did not reach statistical significance although sample sizes were small. The relationships between the change in colon transit and symptoms were not reported.

In summary, based on existing literature, gut transit times do not appear to be altered in the majority of IBS patients, ${ }^{92}$ although it seems to differentiate IBS subtypes-that is, GI transit is more rapid in those with IBS-D, bowel urgency and looser stools, while slower transit is more likely to be seen in patients with IBS-C, hard stools and bloating. Scintigraphy has been shown to be reproducible in healthy individuals, but this may be difficult to assess in IBS patients unless performed in a relatively short space of time because IBS patients commonly transition between subtypes, particularly IBS-M with mixed bowel habit, and IBS-C. ${ }^{112}$ Based on a limited number of studies, changes in colonic transit in response to drug treatment appear to correlate consistently with stool form, and to a lesser extent stool frequency and ease of stool passage. However, as pointed out earlier, none of these symptoms has been shown to be predictive of IBS severity or HRQoL. Thus, gut transit is a good surrogate marker for stool form and, therefore, may be a useful tool to evaluate drugs which affect bowel habit in IBS, but is not likely to be an ideal surrogate marker for overall IBS severity, abdominal pain and HRQoL.

\section{Strengths and limitations of the two most commonly used human biomarkers for IBS symptoms}

Perceptual sensitivity to colorectal distension is associated with the presence of IBS, but is probably 
only moderately correlated with the presence and severity of abdominal pain (correlation coefficients between 0.3 and 0.5 ) and much less with global IBS symptoms. It therefore has some predictive validity when evaluating drugs with known analgesic or antihyperalgesic effects. However, similar to GI transit measurements, the value of such studies to predict the effectiveness of a candidate compound to reduce global IBS symptoms in RCTs, and to form the basis for so-called go/no-go decisions in IBS drug development is limited.

GI transit measures performed in IBS patients probably have the best predictive validity for specific IBS symptoms, such as stool form and possible ease of defecation (straining, urgency), even though correlation coefficients have not been reported. It is likely that these tests are also predictive in slow transit constipation in normalising transit and reducing the symptom of constipation. GI transit measures are also essential in determining possible undesired side effects of certain drugs, in particular constipation. However, in view of the normal overall colonic transit times seen in the majority of IBS patients without diarrhoea-predominant symptoms, ${ }^{92}$ and the poor predictive value of bowel movements, stool form and stool frequency for global IBS symptom severity and HRQoL, ${ }^{16}{ }^{17}$ the value of such studies to predict the effectiveness of a candidate compound to treat global IBS symptoms as assessed in RCTs is limited. In contrast, transit studies are presumably highly predictive for symptom relief by a compound of such disorders as slow transit constipation or diarrhoea.

\section{WHAT IS THE VALIDITY OF ANIMAL MODELS AND MOLECULAR TARGETS IN THESE MODELS FOR SPECIFIC AND GLOBAL IBS SYMPTOMS? Visceral pain models}

As discussed in the previous section, visceral hypersensitivity reflected by enhanced perception of physiological signals from the gut or by enhanced perception of experimental visceral stimuli is commonly considered to play a major role in the pathophysiology of IBS. In contrast to the relatively straightforward modelling of the objective measure of GI transit in animal models, there are several problems with visceral pain models. For example, it is currently not known if this characteristic finding in humans is a reflection of peripheral sensitisation of primary afferent pathways (eg, true visceral afferent hypersensitivity), of central sensitisation, of central pain amplification or a combination of these inter-related mechanisms. Furthermore, readouts from the most commonly used animal models (based on pseudoaffective reflex responses or complex, unlearned behaviours) may also show poor correlations with the human symptom of pain (a subjective pain experience which is highly modulated by cortical influences), despite their face validity.

There are four basic approaches to modelling pain in animals using quantification of (1) segmental (spinal reflexes), (2) complex, unlearned behaviours mediated by brainstem mechanisms (including the visceromotor response to colorectal distension), (3) operant behavioural responses, involving learned operant behaviours ${ }^{113}$ and, most recently, (4) brain imaging approaches in awake and unrestrained animals. ${ }^{114-117}$ Even though technically more demanding, the major advantage of the latter two approaches is the fact that in contrast to (1) and (2) these approaches provide information about higher order cerebral processing of nociceptive information, greatly increasing their validity as animal models of human pain.

The assessment of pseudoaffective reflex responses (and to a lesser degree of behavioural responses) to the controlled distension of different regions of the GI tract and other viscera (oesophagus, stomach, urinary bladder, vagina/cervix and colon/rectum) has become the primary readout for the assessment of visceral pain. Since it was developed by Ness and Gebhart ${ }^{118}$ in 1988, the colorectal distension model of visceral pain has been extensively characterised and has become the standard tool for the assessment of visceral sensitivity in rodents. When applied to rats at pressures comparable with the one producing pain in humans, colorectal distension is aversive and produces a range of autonomic and behavioural pseudoaffective reflexes such as changes in arterial pressure and heart rate (increased arterial blood pressure and tachycardia in awake animals, and decreased arterial blood pressure and bradycardia in anaesthetised animals), ${ }^{118}$ passive avoidance behaviours (immobility, back arching, hind leg spreading) and contraction of the abdominal musculature. This visceromotor response is the most commonly used index of visceral pain response in rats. It is important to point out that in contrast to the subjective experience of pain in humans which involves a network of cortical regions, ${ }^{9}$ the response is a nociceptive brainstem reflex which shows a good correlation with the intensity of the stimulus applied to the colon (pressure or volume). ${ }^{118}$ It can be recorded as a measure of electromyographic signals or counts of the number of spike bursts, but also as manometric changes in balloon pressure. ${ }^{119}$ It has been recently adapted to mice. ${ }^{120-122}$ Electrophysiological recordings from primary afferent neurons or second order spinal neurons has also been used as more direct evidence of afferent activity. ${ }^{123} 124$

The validation of preclinical animal models for the study of visceral hyperalgesia has almost exclusively relied on such methods measuring the pseudoaffective response to colorectal distension in experimental models of visceral hypersensitivity. Local treatment with inflammatory agents or irritants has been repeatedly shown to trigger acute hypersensitivity to distension of different parts of the gut, and these acute models probably have good validity for such human disorders as acute gastroenteritis or flare of inflammatory bowel disease. Certain interventions, such as stress in the neonatal period, ${ }^{125}{ }^{126}$ and the delayed effects of stress, ${ }^{127}{ }^{128}$ gut inflammation ${ }^{129}$ or infestation 
with parasites, ${ }^{130}{ }^{131}$ have demonstrated the development of chronic visceral sensitivity, way beyond the time of the interventions, thereby increasing the face validity of these models for a chronic disorder, such as IBS. However, the translation of pseudoaffective responses to noxious colorectal distension in rodents as an index of visceral hypersensitivity, and abdominal pain in humans, is complicated by several factors: (1) stimulus intensities (more than twice as high in rodents) and balloon dimensions differ greatly between preclinical and clinical applications of the test; (2) humans and rodents differ in the central processing and modulation of nociceptive signals from the GI tract; ${ }^{9}$ and (3) a significant contribution to the human pain response is factors related to cognitive and emotional dimensions related to the experimental situation. As mentioned earlier, brainstemmediated reflex responses are less likely to capture such cortical inputs compared with operant behavioural pain models. ${ }^{118} 119$ Novel approaches such as operant behavioural assays ${ }^{113}{ }^{132-134}$ or functional brain imaging of integrated brain responses to nociceptive stimuli ${ }^{114-117}$ may be superior as animal models for visceral hypersensitivity and IBS symptoms.

\section{GI transit studies/faecal pellet output}

In general, the techniques used to record GI motility or measure transit in animals provide measurement of gastric emptying, duodenojejunal migrating motor complex patterns and colonic motility and transit (reviewed in Canilleri et $a l^{135}$ ). The methods established for evaluation of GI motor and biochemical function in vivo include luminal pressure recordings which determine the contractile pattern in a gut region by measuring the force via a pressure measurement in the lumen and in liquid-filled balloons. Other tests include transit time studies, faecal pellet output, $\mathrm{pH}-$ metry, and imaging such as radiography.

In a recent article, Camilleri et al ${ }^{135}$ reviewed the animal models that have been validated for the study of the effects of pharmacological agents on GI motility. Stress, under different forms, can affect gastric emptying, motor patterns, and colonic motility and transit. Stressors such as restraint, acoustic stress, cold stress, combined acoustic and cold stress, or passive avoidance have been associated with delayed gastric emptying. Acute stress exposure can trigger alteration in migrating motor complex patterns, and has been used to stimulate colonic motility, colonic transit and faecal excretion in rats. In addition, prolonged colonic distension and duodenal infusion of lipids were found to inhibit gastric emptying. Also, inhibition of colonic motility and transit can be induced by pharmacological agents such as $\alpha_{2}$-adrenergic and $\mu$-opioid receptor agonists. In contrast to the readouts from colorectal distension experiments, which differ greatly between rodents and human subjects, objective GI transit measurements translate more directly between preclinical and clinical models.

\section{Anxiety-like behaviours}

Extensive epidemiological evidence has demonstrated the common comorbidity of IBS with anxiety disorders and to a lesser degree with depression. ${ }^{136}$ More recent evidence has demonstrated an important role of symptom- or illnessrelated anxiety in the symptom severity in IBS, ${ }^{16}{ }^{137}$ and this is illustrated in fig 2. Furthermore, recent brain imaging studies implicate alterations in corticolimbic interactions in IBS patients. ${ }^{9} 8138$ Although peripheral and central sensitisation may play a role in visceral hypersensitivity in this patient population, a significant component of the chronically enhanced perceptual response to gut stimuli may be due to altered affective (symptom-related anxiety) and cognitive modulation (hypervigilance, catastrophising) of visceral sensation. To date, the role of the limbic system in the modulation of visceral nociception in preclinical studies has been indirectly demonstrated in animal models of stress-induced visceral hypersensitivity using neonatal maternal separation stress, ${ }^{125} 126139$ neonatal pain ${ }^{140}$ or acute/chronic stress in adult animals. ${ }^{128} 141$ In these models, enhanced stress responsiveness was associated with increased anxiety-like behaviours measured as the response to openfield exposure. However, most of the animal models of enhanced visceral nociception associated with chemical inflammation or irritation, mechanical distension or infection have not been characterised for changes in anxiety level. There are currently a number of paradigms that are being used to measure anxiety in animals or detect the anxiolytic action of different classes of compounds, including the measurement of exploratory behaviour in response to novelty (plus-maze, openfield, light-dark transition), social behaviours (social interaction, separation-vocalisation) or the acoustic startle response. ${ }^{142}$ Even though the predictive validity of these tests for human forms of anxiety is well established, ${ }^{143}$ little is known about the predictive validity of such measures for IBS symptom-related anxiety or global IBS symptoms.

\section{Predictive validity of animal models for IBS symptoms}

As shown in table 3 , for a selective number of IBS candidate drugs, the predictive validity of preclinical transit models has been relatively good-for example, similar effects of $5-\mathrm{HT}_{3}$ and $5-\mathrm{HT}_{4}$ receptor modulators of octreotide and of $\mu$-opioid receptor agonists were observed in both preclinical and human experimental models. For the two serotonin receptor drugs, this predictive validity of preclinical models also applies to overall IBS symptoms, as assessed by a modest beneficial effect on a global end point. In contrast, the predictive validity of preclinical visceral pain models has been less consistent. For example, while robust visceroanalgesic and antihyperalgesic effects of the $\kappa$-opioid agonist fedotozine were seen in several rodent models, effects in human visceral sensitivity testing were largely negative, and 


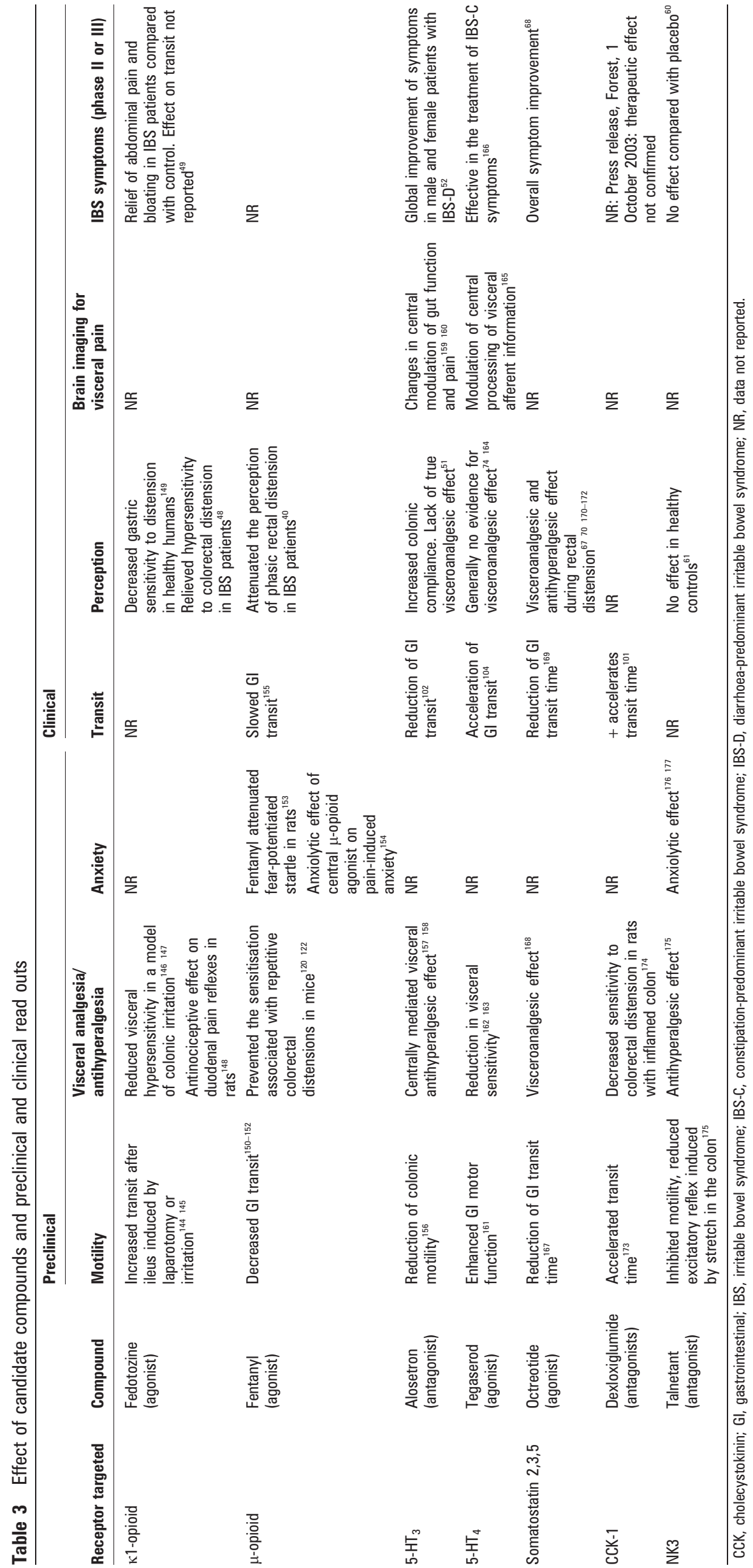


results of phase II clinical trials were mixed. In the case of the $5-\mathrm{HT}_{3}$ receptor antagonist alosetron, visceral antihyperalgesic effects were seen in preclinical testing (presumably mediated by central $5-\mathrm{HT}_{3}$ receptors), no visceroanalgesic effects were seen in human visceral pain tests, while robust effects were seen on clinical symptoms. For the 5$\mathrm{HT}_{4}$ receptor agonist tegaserod, visceroanalgesic effects were seen in preclinical models, while no effects were seen in human patient visceral pain assessments. Nevertheless, tegaserod has been shown to be effective in reducing clinical symptoms. For the non-selective somatostatin receptor antagonist octreotide, the robust effects seen in preclinical models were replicated in human visceral pain testing, and preliminary results suggest that this may translate into relief of IBS symptoms. ${ }^{68}$ Finally, the visceroanalgesic effect of the $\mathrm{NK}_{3}$ receptor antagonist talnetant seen in a small number of preclinical studies ${ }^{175}$ did not translate into positive results in human visceral pain testing, and no effects on IBS symptoms were observed in well-designed clinical trials. Even though in-depth analysis of each compound (eg, doses, plasma levels, etc.) can yield important information regarding the positive or negative prediction by the respective preclinical model, it is clear that current preclinical pain models in rodents, using pseudoaffective reflex responses as a readout for visceral pain, have generally shown inconsistent predictive validity for IBS symptoms.

\section{Emerging strategies-challenges}

Even though it is conceivable that differences in dosing in preclinical, human biomarker and clinical trials may be responsible in part for the poor correlations between results obtained in these different tests of IBS drugs, we believe that the problem is more related to the shortcomings of the drug development strategy. As discussed in detail above and illustrated in figs 1 and $2 \mathrm{~A}$, the traditional drug development strategy taken by the majority of pharmaceutical companies is well suited to produce effective drugs to treat symptoms of constipation and diarrhoea, but much less effective in identifying compounds early in development with high impact on global IBS symptoms. Considering that abdominal pain is a major predictor of IBS symptom severity and presumably HRQoL impairment, this is clearly a limitation of current strategies. Factors that have contributed to the current model of drug development include a more complete understanding of the enteric nervous system and its role in the regulation of GI motility and secretion (compared with the limited understanding of central mechanisms involved in the modulation of these functions, and in pain modulation), and, therefore, a primary focus on peripheral drug targets in the GI tract. This has resulted in a focus on preclinical and clinical models for modifying GI transit, despite the fact that transit alterations in IBS patients are small and inconsistent, and probably have only a small role in global IBS symptom generation. It has also resulted in the focus on preclinical models of peripheral sensitisation of visceral afferent pathways, using models of questionable validity for functional GI syndromes, such as chemical sensitisation, massive inflammation or infestation with parasites, using reflex responses (as opposed to operant behaviours or brain responses) as readouts of abdominal pain, which do not have a good predictive validity for the complex human experience of pain and discomfort. Based on the model summarised in fig 2A, we would like to make the following predictions:

- A candidate drug will be most effective if it affects more than one of the component symptoms shown in the lower half of the figure, since each of these symptoms contributes at best $10 \%$ to global symptoms. In other words, a compound that reduces abdominal pain AND bloating, as well as normalises defecation-related symptoms will be more effective than one that only affects one of these symptoms. Similarly, a compound that in addition affects symptom-related anxiety will have the greatest impact on global symptoms and QoL improvement. This obvious conclusion implies that compounds would be most effective if they have demonstrated effectiveness on more than one human biomarker and more than one preclinical model. If this assumption is correct, then based on their preclinical effectiveness, drugs such as somatostatin receptor agonists, or antagonists for the corticotropin-releasing factor 1 should have a greater impact on reducing IBS symptom severity than peripherally restricted prokinetic agents or pure antidiarrhoeals, even though these drugs may be highly effective in treating these individual symptoms. The $5-\mathrm{HT}_{3}$ receptor antagonist alosetron, one of the few examples of a compound that has gone through all the stages of drug development, is in line with this hypothesis: $5-\mathrm{HT}_{3}$ receptor antagonists have been shown in animal models to have anxiolytic, antihyperalgesic and transitreducing properties, ${ }^{75}$ even though only one of these properties (GI transit reduction) has been demonstrated in human experimental models. However, the drug was associated with reduced activity in limbic brain circuits, and this reduction correlated with a reduction in global IBS symptoms. ${ }^{160}$ It remains to be determined if symptom- or illness-related anxiety, an important factor which influences both IBS symptom severity and IBS-related OoL impairment, ${ }^{17} 137178$ can be affected secondarily simply by normalising altered defecation (eg. by reducing urgency or the sensation of fullness), or if this abnormality reflects a primary central alteration which needs to be targeted directly. In other words, in a head to head comparison, is a compound such as Imodium equally effective in reducing global IBS symptoms as alosetron (suggesting that it is primarily the antidiarrhoeal effect) or is alosetron more effective, because of its independent effects on motility, secretion, central pain 
Basic neuroscience: biomarker development
Drug discovery
Drug development
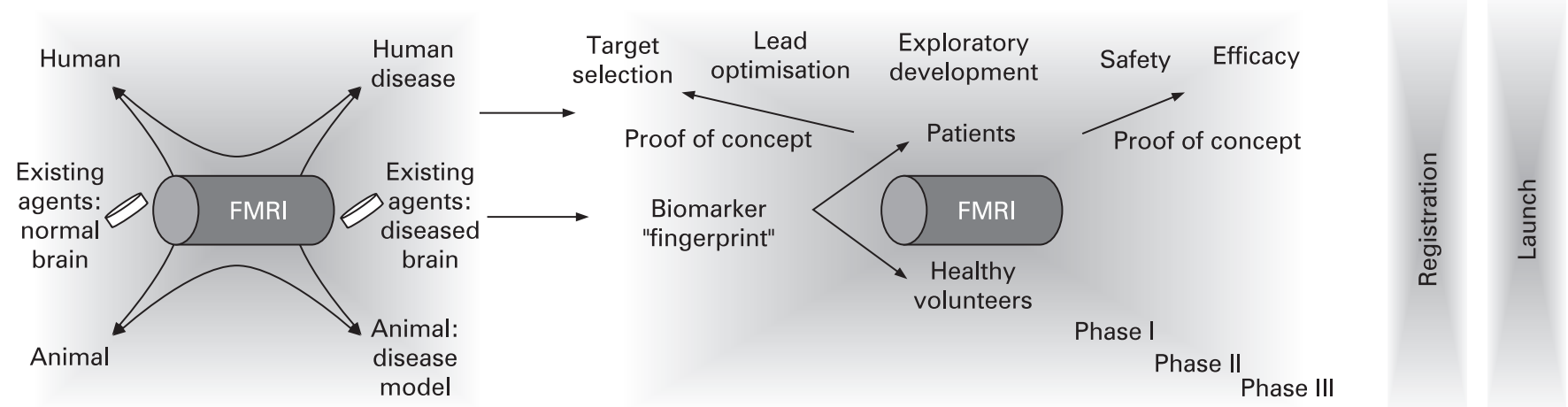

Figure 3 Functional brain imaging in drug discovery. Known agents and procedures are used to develop disease-relevant biomarkers by crossvalidation of data between normal animal and human brain function and between animal disease models and human disease. This process also provides new understanding of brain system functions and aids pharmacological target identification for drug discovery. The effect of a new compound on the previously established biomarker can then be assessed, effective doses evaluated and regulatory evidence collected in efficient POC studies. These POC studies in small cohorts of patients and healthy volunteers can validate our understanding of a mechanism of action and give initial data on efficacy. Reproduced with permission from Wise and Tracey. ${ }^{182}$

amplification and symptom-related anxiety. Similarly, is the peripherally acting chloride channel opener lubiprostone, which is highly effective in treating chronic constipation, equally effective in treating global IBS symptoms?

- Animal models that mimic more than one symptom of the human syndrome and include operational aspects, rather than being limited to reflex responses (eg, have greatest face validity), should have the greatest predictive validity for effective IBS drug development. For example, several rodent models have been reported which demonstrate anxiety-like behaviour, enhanced stress sensitivity, transit abnormalities and visceral hyperalgesia. ${ }^{125} 126128140179180$ On the other hand, models that only mimic an individual symptom or human biomarker would be expected to have the least predictive validity for global symptom severity. Based on the earlier discussions about animal models, rodent models of certain human biomarkers (such as GI transit, stress sensitivity and possibly anxiety) may show a better correlation with the human biomarker than measures of abdominal pain, given the profound differences in CNS mechanisms underlying the human pain/discomfort experience and the rodent nociceptive responses.

- Since the majority of IBS symptoms are subjective human experiences generated by dedicated brain circuits concerned with the processing of visceral homeostatic afferent input to the brain, ${ }^{9}$ direct imaging of abnormalities of the activity and connectivity of these circuits holds significant promise as a biomarker for drug development, both in humans and in animal models (for details, see figs $2 \mathrm{~B}$ and 3). ${ }^{181} 182$ Through the use of brain imaging techniques such as positron emission tomography (PET) and functional MRI (fMRI), considerable progress has been made in the identification and characterisation of specific, yet overlapping brain circuits concerned with pain processing, pain modulation, stress sensitivity, emotional reactivity and central autonomic regulation in humans, ${ }^{9}$ as well as in different animal species, including rodents and non-human primates. ${ }^{115} 183184$ While continued research is needed to consolidate our understanding of these circuitries, many neural models of sensory and affective processing have already emerged as a result of the growing interaction between cognitive neuroscience and clinical research. Using these models, markers of disease states have been defined by determining the degree to which this circuitry is altered in disorders such as anxiety, depression or chronic pain conditions. Such markers have subsequently been used as targets for pharmacological modulation. ${ }^{182} 185$

While pharmacological brain imaging approaches have been used to find surrogate markers of drug efficacy, there are other advantages to using brain imaging in drug discovery and development. For instance, neuroimaging offers the advantage of acquiring objective measures of regional brain activity, while traditional behavioural techniques (ie, subject report, reaction time and accuracy) are heavily biased by subjective experience and mood states. Thus, pharmacological imaging may require considerably fewer subjects (12-15 vs hundreds of subjects) to identify significant effects of interest. ${ }^{186}$ Also, many compounds have been pulled from the market due to rare adverse events appearing late in development or during postmarketing surveys, which may be CNS mediated (an example is nausea). Therefore, it may be important 
to determine the degree to which a particular drug may contribute to the CNS side effect profile before the drug is released. By characterising the neural networks involved in the presentation of different side effects such as nausea, depression, anxiety or suicidal ideation, one can determine if the neuroprofile of a drug includes the modulation of these circuits, thereby increasing the risk of such an adverse event.

In short, the ability to identify and characterise abnormalities in terms of activity and signalling mechanisms in the CNS (brain, brainstem and spinal cord) of well-defined IBS populations, identifying the correlates of these abnormalities in the CNS of animal models, evaluating the drug effects and dose requirements on both human and animal targets, and the ability to perform relatively small phase IIa studies in patients to screen compounds before taking the most promising compounds into full-scale clinical trials are all potential benefits of this approach (for a summary, see fig 3). In light of these advantages, pharmacological brain imaging approaches in IBS patients have been reported for alosetron, ${ }^{160}$ amitriptyline ${ }^{187}$ and tegaserod, ${ }^{165}$ and analogous phase IIa studies are currently underway to evaluate the effects of receptor antagonists for corticotropin-releasing factor and substance P. Preliminary reports suggest the feasibility of identifying brain circuit activation in response to visceral stimuli in rodents. ${ }^{114-117}$

\section{SUMMARY AND CONCLUSIONS}

Despite the considerable efforts by the pharmaceutical industry, the success of IBS drug development has been disappointing to patients, industry and involved investigators alike. As we tried to emphasise in the discussions above, part of this disappointment is related to the incomplete understanding of IBS pathophysiology, and to limitations intrinsic to the traditional drug development strategy taken. Primary focus on targets related to specific symptoms, and reliance on limited preclinical and clinical models has in general been quite successful in the development of drugs aimed at treating constipation and diarrhoea, but much less so for abdominal pain or discomfort, or for global IBS symptoms. We propose that translational (bidirectional) pharmacological brain imaging approaches in both animal models and humans (in addition to novel clinical trial designs) have the potential to improve and accelerate the drug discovery and development process, including the identification of more effective compounds, and the dramatic shortening of the drug development process. To validate this novel approach will require considerable investments both by forwardlooking pharmaceutical companies and by public funding agencies.

Acknowledgements: This work was supported in part by a grant from the National Institutes of Health (NIDDK; Office of Research in Women's Health) P50 DK64539. The authors thank Ms Teresa Olivas for invaluable editorial help with the manuscript.

Competing interests: None.

\section{REFERENCES}

1. Pasricha PJ. Desperately seeking serotonin... A commentary on the withdrawal of tegaserod and the state of drug development for functional and motility disorders.Gastroenterology 2007; 132:2287-90.

2. Wilder-Smith $\mathbf{C H}$, Schindler D, Lovblad K, et al. Brain functional magnetic resonance imaging of rectal pain and activation of endogenous inhibitory mechanisms in irritable bowel syndrome patient subgroups and healthy controls. Gut 2004;53:1595-601.

3. Mayer EA, Tillisch K, Bradesi S. Review article: Modulation of the brain-gut axis as a therapeutic approach in gastrointestinal disease. Aliment Pharmacol Ther 2006;24:919-33.

4. Drossman DA, Corazziari E, Delvaux M, et al. ROME III: the functional gastrointestinal disorders. McLean, VA: Degnon Associates, 2006.

5. Mayer EA, Collins SM. Evolving pathophysiologic models of functional gastrointestinal disorders. Gastroenterology 2002;122:2032-48.

6. Taché $\mathbf{Y}$, Martinez V, Wang L, et al. CRF1 receptor signaling pathways are involved in stress-related alterations of colonic function and viscerosensitivity: implications for irritable bowel syndrome. Br J Pharmacol 2004;141:1321-30.

7. Kassinen A, Krogius-Kurikka L, Mäkivuokko H, et al. The fecal microbiota of irritable bowel syndrome patients differs significantly from that of healthy subjects. Gastroenterology 2007; 133:24-33.

8. Spiller R, Aziz 0, Creed F, et al. Guidelines for the management of irritable bowel syndrome. Gut 2007:56:1770-98.

9. Mayer EA, Naliboff BD, Craig AD. Neuroimaging of the brain-gut axis: from basic understanding to treatment of functional $\mathrm{Gl}$ disorders. Gastroenterology 2006;131:1925-42.

10. Fioramonti J, Gebhart GF. In vivo and transgenic animal models used to study visceral hypersensitivity. Neurogastroenterol Motil 2007; 19:20-8.

11. Design of Treatment Trials Committee, Irvine EJ, Whitehead WE, et al. Design of treatment trials for functional gastrointestinal disorders. Gastroenterology 2006:130:1538-51.

12. Dunlop SP, Jenkins D, Neal KR, et al. Randomized, double-blind, placebo-controlled trial of prednisolone in post-infectious irritable bowel syndrome. Aliment Pharmacol Ther 2003;18:77-84.

13. Barbara G, Stanghellini V, De Giorgio $R$, et al. Activated mast cells in proximity to colonic nerves correlate with abdominal pain in irritable bowel syndrome. Gastroenterology 2004;126:693-702.

14. Barbara G, Wang B, Stanghellini V, et al. Mast cell-dependent excitation of visceral-nociceptive sensory neurons in irritable bowel syndrome. Gastroenterology 2007;132:26-37.

15. Vergnolle N, Cellars L, Mencarelli A, et al. A role for proteinaseactivated receptor-1 in inflammatory bowel diseases. J Clin Invest 2004;114:1444-56.

16. Spiegel BM, Strickland A, Chang L. Predictors of patientassessed illness severity in irritable bowel syndrome (IBS) Gastroenterology 2007;132:A-680.

17. Spiegel BM, Gralnek IM, Bolus R, et al. Clinical determinants of health-related quality of life in patients with irritable bowel syndrome. Arch Intern Med 2004;164:1773-80.

18. Azpiroz F, Bouin M, Camilleri M, et al. Mechanisms of hypersensitivity in IBS and functional disorders. Neurogastroenterol Motil 2007:19:62-88.

19. Whitehead WE, Delvaux M. Standardization of barostat procedures for testing smooth muscle tone and sensory thresholds in the gastrointestinal tract. The Working Team of Glaxo-Wellcome Research, UK. Dig Dis Sci 1997;42:223-41.

20. Camilleri M. Testing the sensitivity hypothesis in practice: tools and methods, assumptions and pitfalls. Gut 2002;51:i34-40.

21. Naliboff BD, Munakata J, Fullerton S, et al. Evidence for two distinct perceptual alterations in irritable bowel syndrome. Gut 1997:41:505-12

22. Ritchie J. Pain from distension of the pelvic colon by inflating a balloon in the irritable colon syndrome. Gut 1973;14:125-32.

23. Mertz H, Naliboff B, Munakata J, et al. Altered rectal perception is a biological marker of patients with irritable bowel syndrome. Gastroenterology 1995;109:40-52.

24. Bouin M, Plourde V, Boivin M, et al. Rectal distension testing in patients with irritable bowel syndrome: sensitivity, specificity, and predictive values of pain sensory thresholds. Gastroenterology 2002:122:1771-7.

25. Lembo T, Munakata J, Mertz $\mathrm{H}$, et al. Evidence for the hypersensitivity of lumbar splanchnic afferents in irritable bowel syndrome. Gastroenterology 1994;107:1686-96.

26. Whitehead WE, Crowell MD, Davidoff AL, et al. Pain from rectal distension in women with irritable bowel syndrome: relationship to sexual abuse. Dig Dis Sci 1997:42:796-804. 
27. Verne GN, Robinson ME, Price DD. Hypersensitivity to visceral and cutaneous pain in the irritable bowel syndrome. Pain 2001;93:7-14.

28. Naliboff BD, Berman S, Suyenobu B, et al. Longitudinal change in perceptual and brain activation response to visceral stimuli in irritable bowel syndrome patients. Gastroenterology

2006;131:352-65

29. Whitehead WE, Palsson OS. Is rectal pain sensitivity a biological marker for irritable bowel syndrome: psychological influences on pain perception. Gastroenterology 1998;115:1263-71.

30. Prior A, Sorial E, Sun WM, et al. Irritable bowel syndrome: differences between patients who show rectal sensitivity and those who do not. Eur J Gastroenterol Hepatol 1993;5:343-9.

31. Ng C, Malcolm A, Hansen R, et al. Distension technique influences the relationship between colonic and rectal hypersensitivity in irritable bowel syndrome. Neurogastroenterol Motil 2006;18:206-10.

32. Chang L, Mayer EA, FitzGerald L, et al. Altered perception of somatic stimuli by IBS patients with and without fibromyalgia (FM). Gastroenterology 1997;112:709

33. Accarino AM, Azpiroz F, Malagelada JR. Selective dysfunction of mechanosensitive intestinal afferents in irritable bowel syndrome. Gastroenterology 1995;108:636-43.

34. Munakata J, Naliboff B, Harraf F, et al. Repetitive sigmoid stimulation induces rectal hyperalgesia in patients with irritable bowel syndrome. Gastroenterology 1997:112:55-63.

35. Chang L, Naliboff BD, Labus JS, et al. Effect of sex on perception of rectosigmoid stimuli in irritable bowel syndrome. Am J Physiol Regul Integr Comp Physiol 2006;291:R277-R84.

36. Nozu T, Kudaira M, Kitamori S, et al. Repetitive rectal painful distention induces rectal hypersensitivity in patients with irritable bowel syndrome. J Gastroenterol 2006;41:217-22.

37. Fukudo S, Kanazawa M, Kano M, et al. Exaggerated motility of the descending colon with repetitive distention of the sigmoid colon in patients with irritable bowel syndrome. J Gastroenterol 2002;37:145-50.

38. Lembo T, Naliboff B, Munakata J, et al. Symptoms and visceral perception in patients with pain-predominant irritable bowel syndrome. Am J Gastroenterol 1999:94:1320-6.

39. Chang L, Munakata J, Mayer EA, et al. Perceptual responses in patients with inflammatory and functional bowel disease. Gut 2000:47:497-505

40. Lembo T, Naliboff BD, Matin K, et al. Irritable bowel syndrome patients show altered sensitivity to exogenous opioids. Pain 2000:87:137-47.

41. Dickhaus B, Mayer EA, Firooz N, et al. Irritable bowel syndrome patients show enhanced modulation of visceral perception by auditory stress. Am J Gastroenterol 2003;98:135-43.

42. Whitehead WE, Diamant N, Meyer K, et al. Pain thresholds measured by the barostat predict the severity of clinical pain in patients with irritable bowel syndrome. Gastroenterology 1998;114:859.

43. Lee OY, Mayer EA, Chang $L$, et al. Ratings of sigmoid but not rectal distensions correlate with IBS symptom severity. Gastroenterology 2000;118:A445.

44. Kuiken SD, Lindeboom R, Tytgat GN, et al. Relationship between symptoms and hypersensitivity to rectal distension in patients with irritable bowel syndrome. Aliment Pharmacol The 2005:22:157-64.

45. Zar S, Benson MJ, Kumar D. Rectal afferent hypersensitivity and compliance in irritable bowel syndrome: differences between diarrhoea-predominant and constipation-predominant subgroups Eur J Gastroenterol Hepatol 2006;18:151-8.

46. Izquierdo S, Rey E, Garcia Alonso M, et al. Has the identification of rectal hypersensitivity any implication in the clinical outcome of irritable bowel syndrome? Rev Esp Enferm Dig 2005;97:223-8.

47. Stacher G, Christensen J. Visceral hypersensitivity in irritable bowel syndrome: a summary review. Dig Dis Sci 2006;51:440-5.

48. Delvaux M, Louvel D, Lagier $\mathrm{E}$, et al. The kappa agonist fedotozine relieves hypersensitivity to colonic distension in patients with irritable bowel syndrome. Gastroenterology 1999:116:38-45.

49. Dapoigny M, Abitbol JL, Fraitag B. Efficacy of peripheral $\kappa$ agonist fedotozine versus placebo in treatment of irritable bowel syndrome: a multicenter dose-response study. Dig Dis Sci 1995;40:2244-9.

50. Delvaux M, Beck A, Jacob J, et al. Effect of asimadoline, kappa opioid agonist, on pain induced by colonic distension in patients with irritable bowel syndrome. Aliment Pharmacol The 2004:20:237-46.

51. Delvaux M, Louvel D, Mamet JP, et al. Effect of alosetron on responses to colonic distension in patients with irritable bowel syndrome. Aliment Pharmacol Ther 1998;12:849-55.
52. Camilleri M, Mayer EA, Drossman DA, et al. Improvement in pain and bowel function in female irritable bowel patients with alosetron, a 5-HT3 receptor antagonist. Aliment Pharmacol The 1999:13:1149-59.

53. Thumshirn M, Coulie B, Camilleri M, et al. Effects of alosetron on gastrointestinal transit time and rectal sensation in patients with irritable bowel syndrome. Aliment Pharmacol Ther 2000;14:869-78

54. Zighelboim J, Talley NJ, Phillips SF, et al. Visceral perception in irritable bowel syndrome. Dig Dis Sci 1995;40:819-27.

55. Steadman CJ, Talley NJ, Phillips SF, et al. Selective 5hydroxytryptamine type 3 receptor antagonism with ondansetron as treatment for diarrhea-predominant irritable bowel syndrome: a pilot study. Mayo Clin Proc 1992;67:732-8.

56. Goldberg PA, Kamm MA, Setti-Carraro P, et al. Modification of visceral sensitivity and pain in irritable bowel syndrome by 5 -HT3 antagonism (ondansetron). Digestion 1996:57:478-83.

57. Hammer J, Phillips SF, Talley NJ, et al. Effect of a 5-HT3antagonist (ondansetron) on rectal sensitivity and compliance in health and the irritable bowel syndrome. Aliment Pharmacol Ther 1993; 7:543-51.

58. Prior A, Read NW. Reduction of rectal sensitivity and postprandial motility by granisetron, a 5 HT3-receptor antagonist, in patients with irritable bowel syndrome. Aliment Pharmacol Ther 1993;7:175-80.

59. Evans BW, Clark WK, Moore DJ, et al. Tegaserod for the treatment of irritable bowel syndrome. Cochrane Database Syst Rev 2004:CD003960.

60. Dukes GE, Dewit OE, Sanger GJ, et al. Lack of effect of the NK3 receptor antagonist, talnetant SB223242 on symptoms of IBS: results of 2 randomized, double-blind, placebo-controlled dose ranging trials. Gastroenterology 2007;132;A60.

61. Houghton LA, Atkinson W, Lockhart S, et al. Sigmoid-colonic motility in health and irritable bowel syndrome: a role for 5hydroxytryptamine. Neurogastroenterol Motil 2007:19:724-31.

62. Poitras P, Riberdy Poitras M, Plourde V, et al. Evolution of visceral sensitivity in patients with irritable bowel syndrome. Dig Dis Sci 2002;47:914-20.

63. Brandt LJ, Bjorkman D, Fennerty MB, et al. Systematic review on the management of irritable bowel syndrome in North America. Am J Gastroenterol 2002;97:S7-26.

64. Rajagopalan M, Kurian G, John J. Symptom relief with amitriptyline in the irritable bowel syndrome. J Gastroenterol Hepatol 1998; 13:738-41.

65. Kuiken SD, Tytgat GN, Boeckxstaens GE. The selective serotonin reuptake inhibitor fluoxetine does not change rectal sensitivity and symptoms in patients with irritable bowel syndrome: a double blind, randomized, placebo-controlled study. Clin Gastroenterol Hepatol 2003;1:219-28.

66. Lee KJ, Kim JH, Cho SW. Gabapentin reduces rectal mechanosensitivity and increases rectal compliance in patients with diarrhoea-predominant irritable bowel syndrome. Aliment Pharmacol Ther 2005;22:981-8.

67. Bradette M, Delvaux M, Staumont G, et al. Octreotide increases thresholds of colonic visceral perception in IBS patients without modifying muscle tone. Dig Dis Sci 1994:39:1171-8.

68. Klooker TK, Beaumont H, Kuiken SD, et al. Octreotide as potential treatment for patients with non-constipated irritable bowel syndrome. Gastroenterology 2005;128:A-93-4.

69. Hasler WL, Soudah HC, Owyang C. A somatostatin analogue inhibits afferent pathways mediating perception of rectal distention. Gastroenterology 1993;104:1390-7.

70. Schwetz I, Naliboff B, Munakata J, et al. Anti-hyperalgesic effect of octreotide in patients with irritable bowel syndrome. Aliment Pharmacol Ther 2004;19:123-31.

71. Coffin B, Farmachidi JP, Rueegg P, et al. Tegaserod, a 5-HT4 receptor partial agonist, decreases sensitivity to rectal distension in healthy subjects. Aliment Pharmacol Ther 2003;17:577-85

72. Kuiken SD, Tytgat GN, Boeckxstaens GE. Review article: drugs interfering with visceral sensitivity for the treatment of functional gastrointestinal disorders - the clinical evidence. Aliment Pharmacol Ther 2005;21:633-51.

73. Zerbib F, Bruley des Varannes S, Oriola RC, et al. Alosetron does not affect the visceral perception of gastric distension in healthy subjects. Aliment Pharmacol Ther 1994;8:403-7.

74. Naliboff BD, Chang L, Crowell MD, et al. Tegaserod increases sigmoid accommodation in female irritable bowel syndrome (IBS) patients. Gastroenterology 2004;126:A-101.

75. Mayer EA, Bradesi S. Alosetron and irritable bowel syndrome. Expert Opin Pharmacother 2003;4:2089-98.

76. Lembo A, Camilleri M. Chronic constipation. N Engl J Med 2003:349:1360-8 
77. Kellow JE, Azpiroz F, Delvaux M, et al. Principles of applied neurogastroenterology: physiology/motility-sensation. In: Drossman DA, Corazziari E, Delvaux M, et al, eds. ROME III: the functional gastrointestinal disorders. McLean, VA: Degnon Associates, 2006:89-160.

78. Camilleri M, Hasler WL, Parkman HP, et al. Measurement of gastrointestinal motility in the Gl laboratory. Gastroenterology 1998;115:747-62

79. Metcalf AM, Phillips SF, Zinsmeister AR, et al. Simplified assessment of segmental colonic transit. Gastroenterology 1987:92:40-7

80. Cremonini F, Mullan BP, Camilleri $\mathrm{M}$, et al. Performance characteristics of scintigraphic transit measurements for studies of experimental therapies. Aliment Pharmacol Ther 2002;16:1781-90.

81. Horikawa $\mathbf{Y}$, Mieno $\mathrm{H}$, Inoue $\mathrm{M}$, et al. Gastrointestinal motility in patients with irritable bowel syndrome studied by using radioopaque markers. Scand J Gastroenterol 1999;34:1190-5.

82. Gorard DA, Libby GW, Farthing MJ. Effect of a tricyclic antidepressant on small intestinal motility in health and diarrheapredominant irritable bowel syndrome. Dig Dis Sci 1995;40:8695

83. Nielsen $\mathbf{O H}$, Gjorup T, Christensen FN. Gastric emptying rate and small bowel transit time in patients with irritable bowel syndrome determined with $99 \mathrm{mTc}$-labeled pellets and scintigraphy. Dig Dis Sci 1986;31:1287-91

84. Vassallo M, Camilleri M, Phillips SF, et al. Transit through the proximal colon influences stool weight in the irritable bowel syndrome. Gastroenterology 1992;102:102-8.

85. Cann PA, Read NW, Brown C et al. Irritable bowel syndrome: relationship of disorders in the transit of a single solid meal to symptom patterns. Gut 1983;24:405-11.

86. Hutchinson R, Notghi A, Smith NB, et al. Scintigraphic measurement of ileocaecal transit in irritable bowel syndrome and chronic idiopathic constipation. Gut 1995;36:585-9.

87. Heaton KW, Radvan J, Cripps $\mathrm{H}$, et al. Defecation frequency and timing, and stool form in the general population: a prospective study. Gut 1992;33:818-24.

88. O'Donnell LJ, Virjee J, Heaton KW. Detection of pseudodiarrhoea by simple clinical assessment of intestinal transit rate. BMJ 1990;300:439-40.

89. Davies GJ, Crowder M, Reid B, et al. Bowel function measurements of individuals with different eating patterns. Gut 1986;27:164-9.

90. Longstreth GF, Thompson WG, Chey WD, et al. Functional bowel disorders. In: Drossman DA, Corazziari E, Delvaux M, et al, eds. ROME III: the functional gastrointestinal disorders. McLean VA: Degnon Associates, 2006:487-556

91. Tillisch K, Labus JS, Naliboff BD, et al. Characterization of the alternating bowel habit subtype in patients with irritable bowel syndrome. Am J Gastroenterol 2005:100:896-904.

92. Bouchoucha M, Devroede G, Dorval E, et al. Different segmental transit times in patients with irritable bowel syndrome and "normal" colonic transit time: is there a correlation with symptoms? Tech Coloproctol 2006;10:287-96.

93. Basilisco G, De Marco E, Tomba C, et al. Bowel urgency in patients with irritable bowel syndrome. Gastroenterology 2007:132:38-44.

94. Serra J, Azpiroz F, Malagelada JR. Impaired transit and tolerance of intestinal gas in the irritable bowel syndrome. Gut 2001:48:14-9.

95. Salvioli B, Serra J, Azpiroz F, et al. Origin of gas retention and symptoms in patients with bloating. Gastroenterology 2005; 128:574-9.

96. Salvioli B, Serra J, Azpiroz F, et al. Impaired small bowel gas propulsion in patients with bloating during intestinal lipid infusion. Am J Gastroenterol 2006;101:1853-7.

97. Hebden JM, Blackshaw E, D'Amato M, et al. Abnormalities of Gl transit in bloated irritable bowel syndrome: effect of bran on transit and symptoms. Am J Gastroenterol 2002:97:2315-20.

98. Chiba T, Kudara N, Sato M, et al. Colonic transit, bowel movements, stool form, and abdominal pain in irritable bowel syndrome by treatments with calcium polycarbophil. Hepatogastroenterology 2005;52:1416-20.

99. Bouchoucha $\mathbf{M}$, Faye A, Devroede G, et al. Effects of oral pinaverium bromide on colonic response to food in irritable bowel syndrome patients. Biomed Pharmacother 2000;54:381-7

100. Passaretti S, Guslandi M, Imbimbo BP, et al. Effects of cimetropium bromide on gastrointestinal transit time in patients with irritable bowel syndrome. Aliment Pharmacol The 1989;3:267-76.

101. Cremonini F, Camilleri M, McKinzie S, et al. Effect of CCK-1 antagonist, dexloxiglumide, in female patients with irritable bowel syndrome: a pharmacodynamic and pharmacogenomic study. Am J Gastroenterol 2005:100:652-63.

102. Houghton LA, Foster JM, Whorwell PJ. Alosetron, a 5-HT3 receptor antagonist, delays colonic transit in patients with irritable bowel syndrome and healthy volunteers. Aliment Pharmacol Ther 2000;14:775-82.

103. Viramontes BE, Camilleri M, McKinzie S, et al. Gender-related differences in slowing colonic transit by a 5-HT3 antagonist in subjects with diarrhea-predominant irritable bowel syndrome. Am J Gastroenterol 2001;96:2671-9.

104. Prather CM, Camilleri M, Zinsmeister AR, et al. Tegaserod accelerates orocecal transit in patients with constipationpredominant irritable bowel syndrome. Gastroenterology 2000:118:463-8.

105. Camilleri M, McKinzie S, Fox J, et al. Renzapride accelerates colonic transit and improves bowel function in constipation predominant irritable bowel syndrome (C-IBS). Gastroenterology 2004;126:A-642.

106. Tack J, Middleton SJ, Horne MC, et al. Pilot study of the efficacy of renzapride on gastrointestinal motility and symptoms in patients with constipation-predominant irritable bowel syndrome. Aliment Pharmacol Ther 2006;23:1655-65.

107. Houghton LA, Jackson NA, Whorwell PJ, et al. 5-HT4 receptor antagonism in irritable bowel syndrome: effect of SB-207266-A on rectal sensitivity and small bowel transit. Aliment Pharmacol Ther 1999;13:1437-44

108. Camilleri M, Kim DY, McKinzie S, et al. A randomized, controlled exploratory study of clonidine in diarrhea-predominant irritable bowel syndrome. Clin Gastroenterol Hepatol 2003;1:111-21.

109. Kim HJ, Vazquez Roque Ml, Camilleri M, et al. A randomized controlled trial of a probiotic combination VSL\# 3 and placebo in irritable bowel syndrome with bloating. Neurogastroenterol Motil 2005:17:687-96.

110. O'Donnell LJ, Watson AJ, Cameron D, et al. Effect of octreotide on mouth-to-caecum transit time in healthy subjects and in the irritable bowel syndrome. Aliment Pharmacol Ther 1990;4:17781.

111. Andresen V, Camilleri M. Irritable bowel syndrome: recent and novel therapeutic approaches. Drugs 2006;66:1073-88.

112. Drossman DA, Morris CB, Hu Y, et al. A prospective assessment of bowel habit in irritable bowel syndrome in women: defining an alternator. Gastroenterology 2005;128:580-9.

113. Neubert JK, Widmer CG, Malphurs W, et al. Use of a novel thermal operant behavioral assay for characterization of orofacial pain sensitivity. Pain 2005;116:386-95.

114. Wang Z, Bradesi S, Maarek JMI, et al. Functional brain activation and visceral pain measurements in response to colorectal distension in unrestrained conscious rats. Gastroenterology 2007;132:A-717.

115. Holschneider DP, Yang J, Sadler TR, et al. Mapping cerebral blood flow changes during auditory-cued conditioned fear in the nontethered, nonrestrained rat. Neuroimage 2006;29:1344-58.

116. Gao J, Wu X, Owyang $\mathrm{C}$, et al. Enhanced responses of the anterior cingulate cortex neurones to colonic distension in viscerally hypersensitive rats. J Physiol 2006;570:169-83.

117. Li L, Ding J, Ren Z, et al. Expression and colocalization of NADPH diaphorase and Fos in the subnuclei of the parabrachial nucleus in rats following visceral noxious stimulation. Brain Res 2006;1114:41-52

118. Ness TJ, Gebhart GF. Characterization of neurons responsive to noxious colorectal distension in the T13-L2 spinal cord of the rat. J Neurophysiol 1988;60:1419-38.

119. Tammpere A, Brusberg M, Axenborg J, et al. Evaluation of pseudo-affective responses to noxious colorectal distension in rats by manometric recordings. Pain 2005;116:220-6.

120. Larsson M, Arvidsson S, Ekman C, et al. A model for chronic quantitative studies of colorectal sensitivity using balloon distension in conscious mice-effects of opioid receptor agonists. Neurogastroenterol Motil 2003:15:371-81.

121. Kamp EH, Jones RC 3rd, Tillman SR, et al. Quantitative assessment and characterization of visceral nociception and hyperalgesia in mice. Am J Physiol Gastrointest Liver Physiol 2003;284:G434-44.

122. Arvidsson S, Larsson $\mathrm{M}$, Larsson $\mathrm{H}$, et al. Assessment of visceral pain-related pseudo-affective responses to colorectal distension in mice by intracolonic manometric recordings. J Pain 2006:7:108-18.

123. Su X, Julia V, Gebhart GF. Effects of intracolonic opioid receptor agonists on polymodal pelvic nerve afferent fibers in the rat. J Neurophysiol 2000;83:963-70.

124. Booth CE, Kirkup AJ, Hicks GA, et al. Somatostatin sst(2) receptor-mediated inhibition of mesenteric afferent nerves of the 
jejunum in the anesthetized rat. Gastroenterology 2001;121:358-

125. Coutinho SV, Plotsky PM, Sablad M, et al. Neonatal maternal separation alters stress-induced responses to viscerosomatic nociceptive stimuli in rat. Am J Physiol Gastrointest Liver Physiol 2002;282:G307-16

126. Rosztoczy A, Fioramonti J, Jarmay K, et al. Influence of sex and experimental protocol on the effect of maternal deprivation on rectal sensitivity to distension in the adult rat. Neurogastroenterol Motil 2003;15:679-86.

127. Schwetz I, Bradesi S, McRoberts JA, et al. Delayed stressinduced colonic hypersensitivity in male Wistar rats: role of neurokinin-1 and corticotropin-releasing factor-1 receptors. Am J Physiol Gastrointest Liver Physiol 2004;286:G683-91.

128. Bradesi S, Schwetz I, Ennes HS, et al. Repeated exposure to water avoidance stress in rats: a new model for sustained visceral hyperalgesia. Am J Physiol Gastrointest Liver Physio 2005;289:G42-53.

129. Greenwood-Van Meerveld B, Johnson AC, Foreman RD, et al. Spinal cord stimulation attenuates visceromotor reflexes in a rat model of post-inflammatory colonic hypersensitivity. Auton Neurosci 2005;122:69-76.

130. McLean PG, Picard C, Garcia-Villar R, et al. Role of kinin B1 and $\mathrm{B} 2$ receptors and mast cells in post intestinal infection-induced hypersensitivity to distension. Neurogastroenterol Motil 1998;10:499-508.

131. Barbara G, Vallance BA, Collins SM. Persistent intestinal neuromuscular dysfunction after acute nematode infection in mice. Gastroenterology 1997;113:1224-32

132. Jabakhanji R, Foss JM, Berra HH, et al. Inflammatory and neuropathic pain animals exhibit distinct responses to innocuous thermal and motoric challenges. Mol Pain 2006;2:1.

133. Baliki M, Calvo 0, Chialvo DR, et al. Spared nerve injury rats exhibit thermal hyperalgesia on an automated operant dynamic thermal escape task. Mol Pain 2005:1:18.

134. Temple JL, Bradshaw HB, Wood E, et al. Effects of hypogastric neurectomy on escape response to uterine distention in the rat. Pain 1999:Suppl 6:S13-20.

135. Camilleri M, Bueno L, De Ponti F, et al. Pharmacological and pharmacokinetic aspects of functional gastrointestinal disorders. Gastroenterology 2006;130:1421-34.

136. Drossman DA, Camilleri M, Mayer EA, et al. AGA technical review on irritable bowel syndrome. Gastroenterology 2002; 123:2108-31

137. Labus JS, Mayer EA, Chang L, et al. The central role of gastrointestinal-specific anxiety in irritable bowel syndrome: further validation of the Visceral Sensitivity Index. Psychosom Med 2007:69:89-98.

138. Mayer EA, Berman S, Suyenobu B, et al. Differences in brain responses to visceral pain between patients with irritable bowel syndrome and ulcerative colitis. Pain 2005:115:398-409.

139. Schwetz I, McRoberts JA, Coutinho SV, et al. Corticotropinreleasing factor receptor 1 mediates acute and delayed stressinduced visceral hyperalgesia in maternally separated Long Evans rats. Am J Physiol Gastrointest Liver Physiol 2005;289:G704-12.

140. Al-Chaer ED, Kawasaki M, Pasricha PJ. A new model of chronic visceral hypersensitivity in adult rats induced by colon irritation during postnatal development. Gastroenterology 2000;119:1276-85.

141. Gue M, Del Rio-Lacheze C, Eutamene H, et al. Stress-induced visceral hypersensitivity to rectal distension in rats: role of CRF and mast cells. Neurogastroenterol Motil 1997:9:271-9.

142. Lister RG. Ethologically-based animal models of anxiety disorders. Pharmacol Ther 1990;46:321-40.

143. Lang PJ, Davis M, Öhman A. Fear and anxiety: animal models and human cognitive psychophysiology. J Affect Disord 2000:61:137-59.

144. De Winter BY, Boeckxstaens GE, De Man JG, et al. Effects of mu- and kappa-opioid receptors on postoperative ileus in rats. Eur J Pharmacol 1997:339:63-7.

145. Friese N, Chevalier E, Angel F, et al. Reversal by kappa-agonists of peritoneal irritation-induced ileus and visceral pain in rats. Life Sci 1997:60:625-34.

146. Langlois A, Diop L, RiviŠre PJ, et al. Effect of fedotozine on the cardiovascular pain reflex induced by distension of the irritated colon in the anesthetized rat. Eur J Pharmacol 1994;271:245-51.

147. Langlois A, Diop L, Friese N, et al. Fedotozine blocks hypersensitive visceral pain in conscious rats: action at peripheral kappa-opioid receptors. Eur J Pharmacol 1997;324:211-7.

148. Diop L, Riviere PJ, Pascaud X, et al. Peripheral kappa-opioid receptors mediate the antinociceptive effect of fedotozine (correction of fetodozine) on the duodenal pain reflex in rat. Eur J Pharmacol 1994:271:65-71.
149. Coffin B, Bouhassira D, Chollet R, et al. Effect of the kappa agonist fedotozine on perception of gastric distension in healthy humans. Aliment Pharmacol Ther 1996;10:919-25.

150. Topcu I, Ekici NZ, Isik R, et al. The effects of tramadol and fentanyl on gastrointestinal motility in septic rats. Anesth Analg 2006; 102:876-81.

151. Pol 0, Valle L, Sanchez-Blazquez P, et al. Antibodies and antisense oligodeoxynucleotides to mu-opioid receptors selectively block the effects of mu-opioid agonists on intestinal transit and permeability in mice. Br J Pharmacol 1999;127:397-404

152. Pol 0, Ferrer I, Puig MM. Diarrhea associated with intestinal inflammation increases the potency of mu and delta opioids on the inhibition of gastrointestinal transit in mice. J Pharmacol Exp Ther 1994;270:386-91.

153. Fendt M, Mucha RF. Anxiogenic-like effects of opiate withdrawal seen in the fear-potentiated startle test, an interdisciplinary probe for drug-related motivational states. Psychopharmacology 2001;155:242-50

154. Narita M, Kaneko C, Miyoshi K, et al. Chronic pain induces anxiety with concomitant changes in opioidergic function in the amygdala. Neuropsychopharmacology 2006;31:739-50.

155. Corazziari E. Role of opioid ligands in the irritable bowel syndrome. Can J Gastroenterol 1999;13:71A-5A.

156. Gershon MD. Review article: serotonin receptors and transporters - roles in normal and abnormal gastrointestina motility. Aliment Pharmacol Ther 2004;20:3-14.

157. Bradesi S, Lao L, McLean PG, et al. Dual role of 5-HT(3) receptors in a rat model of delayed stress-induced visceral hyperalgesia. Pain 2007;130:56-65.

158. Miranda A, Peles S, McLean PG, et al. Effects of the 5-HT3 receptor antagonist, alosetron, in a rat model of somatic and visceral hyperalgesia. Pain 2006;126:54-63.

159. Mayer EA, Berman S, Derbyshire SW, et al. The effect of the 5HT3 receptor antagonist, alosetron, on brain responses to visceral stimulation in irritable bowel syndrome patients. Aliment Pharmacol Ther 2002;16:1357-66.

160. Berman SM, Chang L, Suyenobu B, et al. Condition-specific deactivation of brain regions by 5 -HT3 receptor antagonist alosetron. Gastroenterology 2002;123:969-77.

161. Galligan JJ, Vanner S. Basic and clinical pharmacology of new motility promoting agents. Neurogastroenterol Motil 2005; 17:643-53.

162. Jiao HM, Xie PY. Tegaserod inhibits noxious rectal distention induced responses and limbic system c-Fos expression in rats with visceral hypersensitivity. World J Gastroentero 2004:10:2836-41.

163. Liang LX, Zhang Q, Qian W, et al. Antinociceptive property of tegaserod in a rat model of chronic visceral hypersensitivity. Chin J Dig Dis 2005;6:21-5.

164. Camilleri M. Review article: tegaserod. Aliment Pharmacol Ther 2001:15:277-89.

165. Kilpatrick L, Labus J, Berman SM, et al. A course of tegaserod treatment modulates CNS processing of visceral afferent information. Gastroenterology 2006;130:A-289-90.

166. Müller-Lissner SA, Fumagalli I, Bardhan KD, et al. Tegaserod, a 5-HT(4) receptor partial agonist, relieves symptoms in irritable bowel syndrome patients with abdominal pain, bloating and constipation. Aliment Pharmacol Ther 2001:15:1655-66.

167. Smedh U, Kaplan JM, Bjorkstrand E, et al. Dual effects of somatostatin analog octreotide on gastric emptying during and after intragastric fill. Am J Physiol 1999:277:R1291-6.

168. Su X, Burton MB, Gebhart GF. Effects of octreotide on responses to noxious colorectal distension in the rat. Gut 2001;48:676-82.

169. Meyer BM, Werth BA, Beglinger C et al. Role of cholecystokinin in regulation of gastrointestinal motor functions. Lancet 1989:2:12-5

170. Chey WD, Beydoun A, Roberts DJ, et al. Octreotide reduces perception of rectal electrical stimulation by spinal afferent pathway inhibition. Am J Physiol Gastrointest Liver Physiol 1995;269:G821-6

171. Mertz H, Walsh JH, Sytnik B, et al. The effect of octreotide on human gastric compliance and sensory perception. Neurogastroenterol Motil 1995; 7:175-85

172. Hasler WL, Soudah HC, Owyang C. Somatostatin analog inhibits afferent response to rectal distension in diarrhea-predominant irritable bowel patients. J Pharmacol Exp Ther 1994;268:1206-11.

173. Varga G, Balint A, Burghardt B, et al. Involvement of endogenous CCK and CCK1 receptors in colonic motor function. $\mathrm{Br} \mathrm{J}$ Pharmacol 2004;141:1275-84.

174. Bonnafous C, Bueno L, Griffin PH, et al. Influence of dexloxiglumide on visceromotor and pain response induced by rectal distension in rats. Gastroenterology 2002:122:A527. 
175. Sanger GJ. Neurokinin NK1 and NK3 receptors as targets for drugs to treat gastrointestinal motility disorders and pain. Br J Pharmacol 2004;141:1303-12.

176. Salome N, Stemmelin J, Cohen C, et al. Selective blockade of NK2 or NK3 receptors produces anxiolytic- and antidepressantlike effects in gerbils. Pharmacol Biochem Behav 2006;83:533-9.

177. Spooren W, Riemer C, Meltzer H. Opinion: NK3 receptor antagonists: the next generation of antipsychotics? Nat Rev Drug Discov 2005:4:967-75

178. Spiegel BM, Strickland A, Chang L. Predictors of patientassessed illness severity in irritable bowel syndrome (IBS). Gastroenterology 2007;132:A680.

179. Li Q. Cellular and molecular alterations in mice with deficient and reduced serotonin transporters. Mol Neurobiol 2006;34:51-66.

180. Million M, Wang L, Stenzel-Poore MP, et al. Enhanced pelvic responses to stressors in female CRF-overexpressing mice. Am J Physiol Regul Integr Comp Physiol 2007;292:R1429-38.

181. Schweinhardt P, Bountra C, Tracey I. Pharmacological fMRI in the development of new analgesic compounds. NMR Biomed 2006;19:702-11.
182. Wise RG, Tracey I. The role of fMRI in drug discovery. J Magn Reson Imaging 2006;23:862-76.

183. Lowe AS, Beech JS, Williams SC. Small animal, whole brain fMRI: innocuous and nociceptive forepaw stimulation. Neuroimage 2007;35:719-28.

184. Martinez V, Wang L, Taché Y. Proximal colon distension induces Fos expression in the brain and inhibits gastric emptying through capsaicin-sensitive pathways in conscious rats. Brain Res 2006;1086:168-80.

185. Matthews PM, Honey GD, Bullmore ET. Applications of fMRI in translational medicine and clinical practice. Nat Rev Neurosci 2006; 7:732-44.

186. Paulus MP, Feinstein JS, Castillo G, et al. Dose-dependent decrease of activation in bilateral amygdala and insula by lorazepam during emotion processing. Arch Gen Psychiatry 2005; 62:282-8

187. Morgan V, Pickens D, Gautam S, et al. Amitriptyline reduces rectal pain related activation of the anterior cingulate cortex in patients with irritable bowel syndrome. Gut 2005:54:601-7.

\section{Editor's quiz: GI snapshot}

\section{Bleeding duodenal ulcer with a right upper quadrant mass}

\section{CLINICAL PRESENTATION}

A 72-year-old woman presented with right upper quadrant abdominal pain and haematemesis. She was known to have gallstones, diabetes and hypertension. On admission, she was afebrile and haemodynamically stable. Clinical examination revealed a tender right upper quadrant egg-sized mass. Her haemoglobin was $9 \mathrm{~g} / \mathrm{dl}$ and white cell count $22 \times 10^{9} / 1$. Liver function tests were deranged (bilirubin $31 \mathrm{mmol} / \mathrm{l}$, alkaline phosphatase (ALP) $833 \mathrm{IU} / 1$, alanine aminotransferase (ALT) $133 \mathrm{IU} / \mathrm{l})$.

She underwent an upper gastrointestinal endoscopy which demonstrated an ulcer at the first part of the duodenum, with a

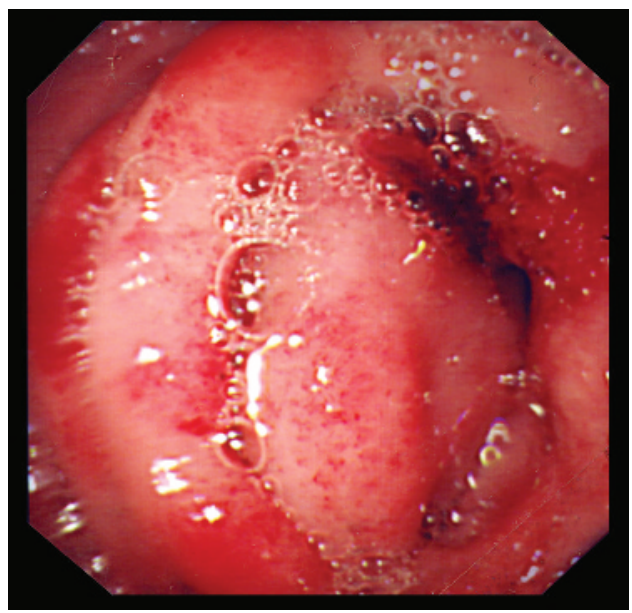

Figure 1 Upper gastrointestinal endoscopic image of an ulcer seen in the duodenum.

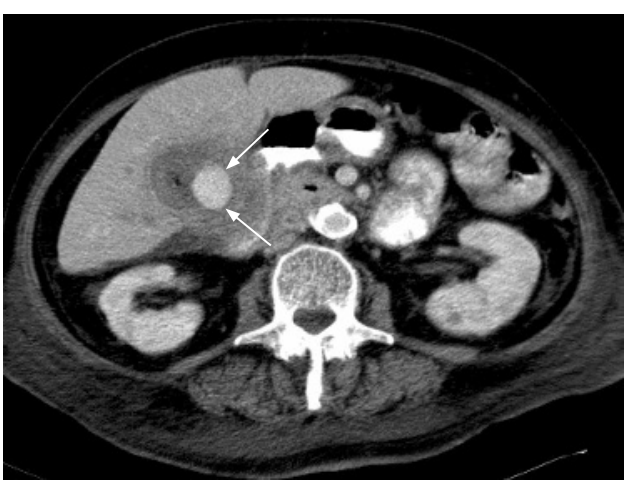

Figure 2 Arterial contrast phase of the abdominal CT image revealing a spherical mass (white arrows).

clot in the base but no active bleeding (fig 1). In the following days, the gastrointestinal bleeding continued. Two subsequent endoscopies performed had similar findings.

An abdominal CT scan revealed a thick-walled gallbladder surrounded by a clot, within which an unexpected $10 \times 3 \mathrm{~cm}$ spherical mass was seen on the arterial contrast phase (fig 2).

\section{QUESTION}

What was the cause of her bleeding? How should it be managed?

See page 423 for answers

\section{F J Foo, ${ }^{1}$ A M Smith, ${ }^{1}$ M Sheridan, ${ }^{2}$ A A Nicholson ${ }^{2}$}

${ }^{1}$ Department of Hepatobiliary Surgery, St James's University Hospital, Leeds, UK;

${ }^{2}$ Department of Radiology, St James's University Hospital, Leeds, UK

Correspondence to: Mr A M Smith, Department of Hepatobiliary Surgery, St James's University Hospital, Beckett Street, Leeds LS9 7TF, UK; andrewm.smith@ leedsth.nhs.uk

Competing interests: None.

Gut 2008;57:404. doi:10.1136/gut.2006.114728 